\title{
Evolution of Nonsteroidal Anti-Inflammatory Drugs (NSAIDs): Cyclooxygenase (COX) Inhibition and Beyond
}

\author{
P. N. Praveen Rao ${ }^{1}$ and Edward E. Knaus ${ }^{2}$. \\ ${ }^{1}$ Department of Chemistry and The Skaggs Institute for Chemical Biology, The Scripps Research Institute, 10550 North \\ Torrey Pines Road, La Jolla, CA 92037, USA. ${ }^{2}$ Faculty of Pharmacy and Pharmaceutical Sciences, University of Alberta, \\ Edmonton, Alberta, Canada.
}

Received, April 28, 2008; Revised, August 27, 2008; Accepted, September 3, 2008; Published, September 13, 2008.

\begin{abstract}
Purpose. NSAIDs constitute an important class of drugs with therapeutic applications that have spanned several centuries. Treatment of inflammatory conditions such as rheumatoid arthritis (RA) and osteoarthritis (OA) starting from the classic drug aspirin to the recent rise and fall of selective COX-2 inhibitors has provided an enthralling evolution. Efforts to discover an ultimate magic bullet to treat inflammation continues to be an important drug design challenge. This review traces the origins of NSAIDs, their mechanism of action at the molecular level such as cyclooxygenase (COX) inhibition, development of selective COX-2 inhibitors, their adverse cardiovascular effects, and some recent developments targeted to the design of effective anti-inflammatory agents with reduced side effects. Methods. Literature data is presented describing important discoveries pertaining to the sequential development of classical NSAIDs and then selective COX-2 inhibitors, their mechanism of action, the structural basis for COX inhibition, and recent discoveries. Results. A brief history of the development of NSAIDs and the market withdrawal of selective $\mathrm{COX}-2$ inhibitors is explained, followed by the description of prostaglandin biosynthesis, COX isoforms, structure and function. The structural basis for COX-1 and COX-2 inhibition is described along with methods used to evaluate COX-1/COX-2 inhibition. This is followed by a section that encompasses the major chemical classes of selective COX-2 inhibitors. The final section describes briefly some of the recent advances toward developing effective anti-inflammatory agents such as nitric oxide donor NO-NSAIDs, dual COX/LOX inhibitors and anti-TNF therapy. Conclusions. A great deal of progress has been made toward developing novel anti-inflammatory agents. In spite of the tremendous advances in the
\end{abstract}

last decade, the design and development of a safe, effective and economical therapy for treating inflammatory conditions still presents a major challenge.

\section{INTRODUCTION}

The fascinating ability to treat fever and inflammation dates back about 3500 (400 B.C.) years ago to a time when the Greek physician Hippocrates prescribed an extract from willow bark and leaves. Later in the 17 th century, the active ingredient of willow bark salicin was identified in Europe. The Kolbe company in Germany started mass producing salicylic acid in 1860. Acetylsalicyclic acid 1 (aspirin) the more palatable form of salicyclic acid was introduced into the market by Bayer in 1899 (1). However, the mechanism of action of anti-inflammatory and analgesic agents such as aspirin and indomethacin $\mathbf{2}$ remained elusive until the early 1960's. This all changed in the seventies, when John Vane discovered the mechanism of action of aspirin and other nonsteroidal anti-inflammatory drugs (NSAIDs) thereby increasing our ability to develop novel anti-inflammatory therapies (2). The success of NSAIDs in treating various inflammatory conditions such as rheumatoid arthritis (RA) and osteoarthritis (OA) validated inhibition of the enzyme prostaglandin $\mathrm{H}$ synthase (PGHS) or cyclooxygenase (COX) as a highly suitable target in anti-inflammatory therapies $(3,4)$. However, the gastrointestinal (GI) toxicities associated with widespread NSAID use proved to be a major drawback during long term therapy (5).

Corresponding Author: Dr. P. N. Praveen Rao, School of Pharmacy, University of Waterloo, Waterloo, Ontario, Canada, N2L 3G1; Email: praopera@uwaterloo.ca 


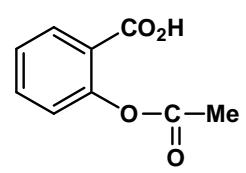

Acetylsalicyclic acid (1)

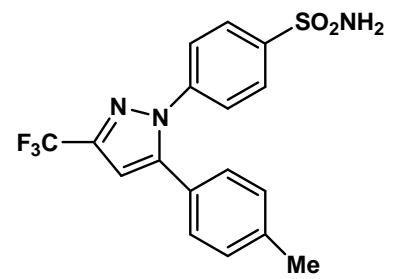

Celecoxib (3)

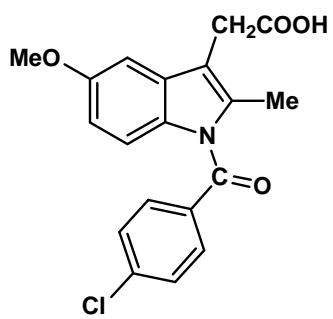

Indomethacin (2)

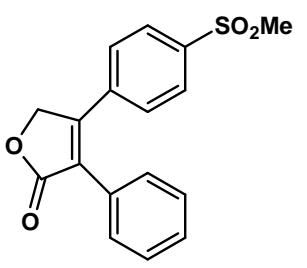

Rofecoxib (4)

Figure 1. Some representative examples of cyclooxygenase $(\mathrm{COX})$ inhibitors.

In the early 90's, Needleman, Simmons and Herschman's group reported the presence of an inducible isoform of the enzyme COX later identified as COX-2 (6-8). This discovery led to the hypothesis that anti-inflammatory prostaglandins (PGs) were produced through constitutive expression of COX-1, whereas the proinflammatory PGs were produced via induction of the COX-2 isoform (9-10). The traditional NSAIDs were known to inhibit both isoforms of COX and their adverse GI toxicities were attributed to the inhibition of gastroprotective PGs produced via the COX-1 pathway. Shortly thereafter, scientists from the academic community and pharmaceutical companies focused their efforts on the design of selective COX-2 inhibitors in order to develop superior anti-inflammatory and analgesic agents with reduced adverse effects compared to traditional NSAIDs. In 1999, G.D. Searle and Pfizer (now Pfizer Inc) launched the first selective COX-2 inhibitor celecoxib 3 (Celebrex $\left.{ }^{\circledR}\right)$. This was followed by the launch of Merck's selective COX-2 inhibitor rofecoxib 4 (Vioxx $\left.{ }^{\circledR}\right)$. In a short period of time both celecoxib and rofecoxib (coxibs) reached blockbuster status achieving sales exceeding one billion U.S. dollars within 15 months post launch (11-15).

In spite of this initial success after the launch of selective COX-2 inhibitors, concerns were raised regarding their adverse cardiovascular events (16). Further studies, conclusively demonstrated that selective COX-2 inhibitors may tip the natural balance between prothrombotic thromboxane $\mathrm{A}_{2} \quad\left(\mathrm{TxA}_{2}\right)$ and antithrombotic prostacyclin $\left(\mathrm{PGI}_{2}\right)$ potentially increasing the possibility of a thrombotic cardiovascular event (17-19). In September 2004 Merck’s Vioxx ${ }^{\circledR}$ was withdrawn from the world-wide market (20). In April of 2005, the US FDA advisory committee overwhelmingly concluded that coxibs increase the risk of cardiovascular events and recommended the suspension of Pfizer's Bextra ${ }^{\circledR}$ (valdecoxib). Celecoxib was allowed to remain in the market place, but with a black box warning indicating a risk of adverse cardiovascular events $(15,21)$. Furthermore, the FDA requested manufacturers of commonly used NSAIDs to make labeling changes to their products suggesting that adverse cardiovascular events could be a general effect for this class of compounds (22). The European Medicines Agency (EMA) was in agreement with the FDA regarding the suspension of Bextra ${ }^{\circledR}$ and labeling changes for coxibs. However, the EMA gave a clean chit to traditional NSAIDs based on their benefit to risk ratio $(23,24)$. Recently, the American Heart Association issued a statement advising prescribing clinicians pertaining to the use of NSAIDs (25). Health Canada recently decided to withdraw Novartis Pharmaceuticals selective COX2 inhibitor lumiracoxib (Prexige $\AA$ ) due to concern regarding its liver toxicity.

The objective of this review is to discuss the COX pathway, enzyme functions, molecular basis of COX-2 inhibition, chemical classification of selective COX-2 inhibitors and their COX$1 / \mathrm{COX}-2$ selectivities. The underlying basis for adverse cardiovascular effects and progress made in the development of novel anti-inflammatory agents having reduced GI and cardiovascular adverse effects will be the focus of this review.

\section{PROSTAGLANDIN BIOSYNTHESIS}

Prostanoids (PG's) are end products of fatty acid metabolism produced via the COX pathway. PG's have long been known to behave as important physiological and pathological mediators implicated in a number of therapeutic areas of interest including inflammation, pain, pyrexia, cancer, glaucoma, male sexual dysfunction, osteoporosis, cardiovascular disease, labor and asthma (26). 


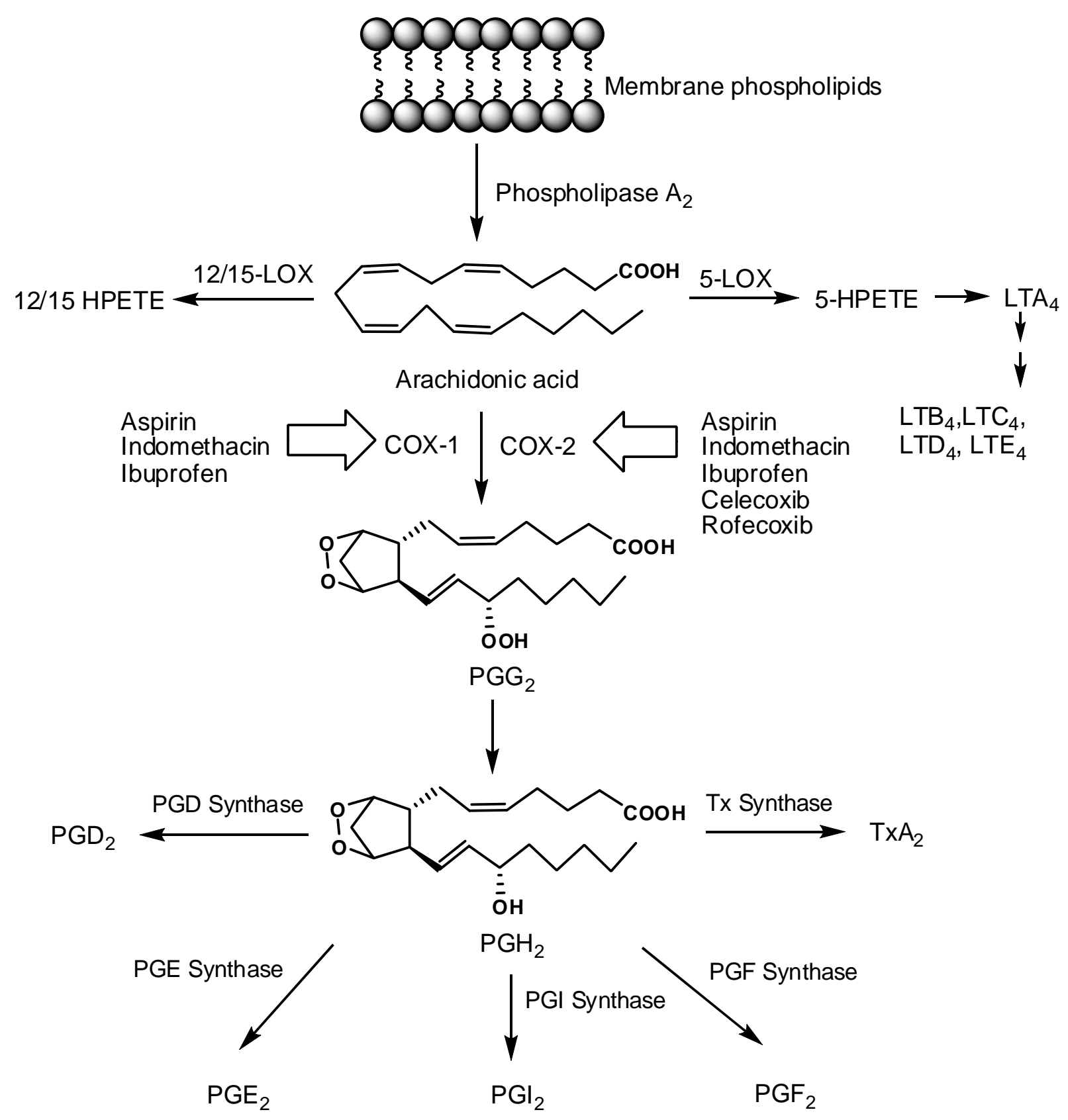

Figure 2. Representative biosynthetic pathway of prostaglandin (PG) biosynthesis from arachidonic acid (AA) via COX1/COX-2 isoform catalysis. The NSAIDs aspirin, indomethacin and ibuprofen are nonselective inhibitors of COX isozymes whereas celecoxib and rofecoxib exhibit selective COX-2 inhibition.

Arachidonic acid (AA), an unsaturated 20-carbon fatty acid embedded in cell membranes as a phospholipid ester, is the precursor for PG synthesis (Figure 2). In response to a wide variety of stimuli, free AA is released which is subsequently converted via COX, lipoxygenase (LOX) and cytochrome P450 enzyme catalysis to various lipid mediators known collectively as eicosanoids (27). In the COX pathway, the two known COX isoforms catalyse the first committed step in the biosynthesis of PG's, thromboxanes (TxA) and other eicosanoids $(11,26,27)$. The production of these eicosanoids is dependent on the availability of AA. The release of AA from membrane phospholipids is mediated by either secretory $\left(\mathrm{sPLA}_{2}\right)$ or cytoplasmic $\left(\mathrm{cPLA}_{2}\right)$ phospholipases. Once AA is released, the COX isoforms catalyze two sequential reactions. The initial COX reaction converts AA to prostaglandin 
$\mathrm{G}_{2} \quad\left(\mathrm{PGG}_{2}\right)$. The subsequent peroxidase (POX) reaction reduces $\mathrm{PGG}_{2}$ to prostaglandin $\mathrm{H}_{2}\left(\mathrm{PGH}_{2}\right)$ which is then converted by various cell specific isomerases and synthases to produce five biologically active primary $\mathrm{PG}$ 's that include prostaglandin $\mathrm{D}_{2}\left(\mathrm{PGD}_{2}\right)$, prostaglandin $\mathrm{E}_{2}\left(\mathrm{PGE}_{2}\right)$, prostaglandin $\mathrm{F}_{2 \alpha}\left(\mathrm{PGF}_{2 \alpha}\right)$, prostacyclin $\left(\mathrm{PGI}_{2}\right)$ and thromboxane $\mathrm{A}_{2}\left(\mathrm{TxA}_{2}\right)$ as illustrated in Figure 2. These products act as secondary messengers by interacting with prostanoid G-protein coupled receptors and other receptors (27).

\section{CYCLOOXYGENASE ISOFORMS, STRUCTURE AND FUNCTION:}

The first purified preparation of the COX enzyme was reported in 1976 (28). More than a decade later COX was cloned in 1988 (29-31). In the 1990's an inducible isoform now called COX-2 was discovered (6-8). COX, originally called prostaglandin $\mathrm{H}$ synthase (PGHS), is the major enzyme responsible for oxidation of $\mathrm{AA}$ to $\mathrm{PGG}_{2}$ and $\mathrm{PGH}_{2}$ (Figure 2). The COX-1 and COX-2 isoforms both catalyze a cyclooxygenase reaction in which the substrate AA and two molecules of molecular $\mathrm{O}_{2}$ are converted to $\mathrm{PGG}_{2}$ and a peroxidase reaction in which $\mathrm{PGG}_{2}$ is reduced to $\mathrm{PGH}_{2}$ by a two electron reduction. These two reactions occur at distinct but structurally and functionally interconnected sites. The COX isoforms are heme containing enzymes that exhibit distinct expression profiles and roles in several physiological processes. The primary structure of COX-1 is comprised of 602 amino acids whereas COX-2 has 604 amino acids. By convention, the residues are numbered according to the ovine or murine COX-1 sequence to standardize structural and functional comparisons between species. The COX-1 and COX-2 isoforms share $60-65 \%$ sequence identity within species and about $85-90 \%$ sequence identity among different species (31). The first crystal structure of ovine COX-1 complexed with the NSAID flurbiprofen was reported in 1994 (32). The structures of human and murine COX-2 are virtually super imposable on ovine COX-1. The COX isoforms are homodimers, with each monomer comprised of three structural domains; a $\mathrm{N}$-terminal epidermal growth factor (EGF) domain, a membrane binding domain (MBD) and a large Cterminal catalytic domain (Figure 3). The COX catalytic reaction occurs in a hydrophobic channel in the core of the enzyme while the peroxidase site is located in the heme containing region near the protein surface. The MBD is made up of four alpha helices with helix D merging into the catalytic domain. These helices surround an opening through which fatty acid substrates and NSAIDs are believed to enter the COX active site. Both COX-1 and COX-2 isoforms are attached to the endoplasmic reticulum (ER) and nuclear envelope. $\mathrm{N}$-glycosylation of the $\mathrm{COX}$ isoforms is required for enzyme folding and activity (27). The COX isoforms have very similar binding site structures, catalytic mechanisms and produce the same biosynthetic products. Some of the differences between human COX-1 and COX-2 are shown in Table 1. The COX-1 and COX-2 monomers both contain a $25 \AA$ hydrophobic channel that originates at the MBD and extends into the core of the catalytic domain. The MBD forms the mouth and first half of the channel, allowing AA and molecular oxygen to enter directly from the apolar compartment of the lipid layer.

The COX-1 isoform is constitutively expressed at high levels in cells and tissues such as endothelium, monocytes, platelets, renal collecting tubules and seminal vesicles indicating that it is developmentally regulated (33). The COX-2 enzyme is induced by mediators of inflammation such as lipopolysaccharides (LPS), interlukin-1 (IL$1)$, tumor necrosis factor-alpha (TNF- $\alpha$ ) in a wide variety of cells and tissues such as vascular endothelium, osteoclasts, rheumatoid synovial endothelial cells, monocytes and macrophages. Recent studies have indicated that constitutively expressed COX-2 plays specific functions in reproduction, renal physiology, bone resorption and neurotransmission (34-37).

\subsection{COX isoforms and inflammation}

Traditional NSAIDs prescribed to control joint pain and treat inflammatory conditions such as RA and OA produce their anti-inflammatory and analgesic effects by nonselective inhibition of COX activity. During the inflammatory process, the COX-1 mRNA and protein activity do not change whereas a dramatic increase in COX-2 levels occurs leading to increased production of proinflammatory PGs. 

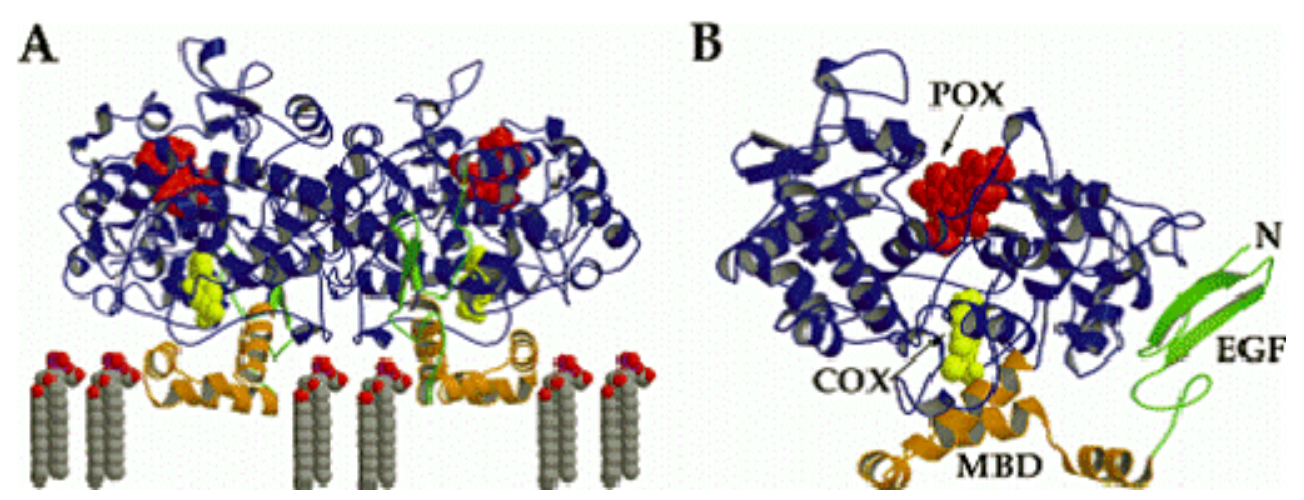

Figure 3. A. Ribbon diagram of the ovine COX-1 homodimer with flurbiprofen bound within the COX active site. B. Ribbon diagram of ovine COX-1 monomer with flurbiprofen bound indicating the locations of the COX and peroxidase (POX) active sites and the EGF and MBD domains. Flurbiprofen is represented as a yellow space filling model [reprinted with permission, from the Annual Review of Biochemistry, Volume 69 (c) 2000 by Annual Reviews www.annualreviews.org, ref 27].

Table 1: Comparison of the COX-1 and COX-2 isoforms

\begin{tabular}{lll}
\hline Properties & COX-1 & COX-2 \\
\hline & & \\
Gene size & $22 \mathrm{~kb}$ & $8.3 \mathrm{~kb}$ \\
Exons & 11 & 10 \\
Chromosome & $9 \mathrm{q} 32-\mathrm{q} 33.3$ & $1 \mathrm{q} 25.2-\mathrm{q} 25.3$ \\
mRNA & $2.8 \mathrm{~kb}$ & $4.1 \mathrm{~kb}$ \\
mRNA regulation & constitutive & inducible \\
Inducers & - & LPS, cytokines, phorbol esters \\
Molecular weight & $70 \mathrm{kD}$ & $70-72 \mathrm{kD}$ \\
Localization & Endoplasmic reticulum & Nuclear membrane, \\
& $($ ER) & ER \\
Cofactors & $1 \mathrm{~mol}$ of heme & $1 \mathrm{~mol}$ of heme \\
Glycosylation & $-\mathrm{N}, 3$ sites & $-\mathrm{N}, 3$ or 4 sites $\quad$ AA, $\gamma$-linolenic acid, $\alpha$-linolenic acid, \\
Substrate specificity & AA, $\gamma$-linolenic acid & \\
eicosapentenoic acid & & 12 mmol of AA/mg/ml \\
Activity & 23 mmol of AA $/ \mathrm{mg} / \mathrm{ml}$ &
\end{tabular}

The GI side effects associated with traditional NSAIDs are due to the inhibition of gastroprotective $\mathrm{PGs}$ synthesized via the $\mathrm{COX}-1$ pathway $(38,39)$. The expression of COX-2 has been studied extensively in animal models of inflammation which provided strong evidence that induction of COX-2 enzyme is associated with inflammation. The COX-1 enzyme does not appear to be affected by the inflammatory process since similar levels of mRNA and protein are detected in both normal and inflamed tissue in animal models.
PGs such as $\mathrm{PGE}_{2}$ and $\mathrm{PGI}_{2}$ produced via the COX2 pathway magnify the degree of inflammation initiated by other mediators of inflammation such as histamine and bradykinin leading to increased vascular permeability and edema (40-43). COX-2 is not detectable in normal tissue but is detectable after induction by inflammatory stimuli. Selective COX-2 inhibitors exhibit good anti-inflammatory and analgesic activities in various animal models. 


\subsection{COX and the gastrointestinal tract (GI)}

In humans and other species, it has been shown that COX-1 but not COX-2 is expressed constitutively throughout the GI tract (44). PGs such as $\mathrm{PGE}_{2}$ and $\mathrm{PGI}_{2}$ produced by $\mathrm{COX}-1$ are known to exhibit cytoprotective effects on the GI mucosa by reducing gastric acid secretion by parietal cells in the stomach, increase mucosal blood flow, and stimulate the release of viscous mucus. Selective COX-2 inhibitors are efficient anti-inflammatory agents with less GI toxicity due to their selective inhibition of COX-2 and sparing action on COX-1. However, there are reports of constitutive COX-2 expression in healthy human and rabbit GI mucosa (45). It has also been reported that during the GI ulcer formation process, COX-2 may be induced and that it could play a role in the GI healing (46). Clinical trials indicate short term GI safety benefits occur with selective COX-2 inhibitors compared to traditional NSAID therapy (47-49). However, long term studies are limited and inconclusive.

\subsection{COX and the kidney}

PGs regulate vascular tone and normal blood flow thereby maintaining renal function (50). Studies using animal models of renal diseases, and patients with congestive heart failure, liver cirrhosis or renal insufficiency have shown that $\mathrm{PGE}_{2}$ was primarily responsible for maintaining normal kidney function (10). In humans COX-1 is constitutively expressed in the vasculature, the collecting ducts and the loop of Henle, whereas low levels of COX-2 are expressed constitutively in the macula densa, epithelial cells lining the ascending loop of Henle and medullary interstitial cells of the renal papillae (11). The COX-2 enzyme is involved in normal renal development and COX-2 deficient mice develop severe nephropathy $(51,52)$. Studies have shown that NSAID-induced sodium retention in healthy and elderly patients is mediated by the inhibition of COX-2, whereas a decreased glomerular filtration rate is associated with inhibition of COX-1. These studies confirm that both COX isoforms are involved in renal physiology (53). Recent studies have indicated, among a group of current selective COX-2 inhibitors, that rofecoxib is associated with increased renal and arrhythmia risks $(54,55)$.

\subsection{COX and the cardiovascular system}

It is well known that the COX-1 isoform is constitutively expressed in platelets and is responsible for the formation of pro-aggregatory $\mathrm{TxA}_{2}$. In contrast, the synthesis of anti-aggregatory $\mathrm{PGI}_{2}$ in endothelial cells is primarily catalyzed by COX-2 (56). Aspirin acts as an irreversible inhibitor of COX-1 in platelets by acetylating the Ser530 residue. This leads to blocking of $\mathrm{TxA}_{2}$ synthesis resulting in a reduced risk of thrombosis. COX mediated vascular control has been demonstrated in COX-1 and COX-2 knock out animal models. Mice deficient in COX-2 die within 48 hours after birth with a patent ductus arteriosus. Similarly, mice deficient in both isoforms of COX die within 12 hours of birth due to a similar condition (57). Soon after the launch of selective COX-2 inhibitors celecoxib and rofecoxib a cautionary flag was raised regarding the use of COX-2 inhibitors in patients at risk for cardiovascular morbidity such as myocardial infarction (16). The argument was that $\mathrm{PGI}_{2}$ is a vasodilator and a potent inhibitor of platelet aggregation produced by COX-2 at the sites of inflammation. Although selective COX-2 inhibitors have no effect on $\mathrm{TxA}_{2}$ production, by decreasing $\mathrm{PGI}_{2}$ production, selective $\mathrm{COX}-2$ inhibitors may tip the natural balance between prothrombotic $\mathrm{TxA}_{2}$ and anti-inflammatory $\mathrm{PGI}_{2}$ that could potentially increase the possibility of a thrombotic cardiovascular event. In addition, there are other indications of a protective role for $\mathrm{PGE}_{2}$ and $\mathrm{PGI}_{2}$ derived from the COX-2 pathway pertaining to oxidative damage (58). Accordingly, both COX-1 and -2 derived PGs appear to have a profound role in the regulation of vascular homeostasis. The VIGOR trial for rofecoxib showed increased risk of cardiovascular events compared to naproxen. However, the CLASS trial for celecoxib and the TARGET trial for lumiracoxib did not indicate an increased risk of cardiovascular events (47-49). While the debate continues on cardiovascular risks associated with COX-2 inhibitors, indications are clear that COX-2 selective inhibitors as a class are associated with cardiovascular risks (59). The argument that selective COX-2 inhibitors tip the balance between prothrombotic $\mathrm{TxA}_{2}$ and anti-inflammatory $\mathrm{PGI}_{2}$ was validated experimentally by an elegant study recently. In this regard, FitzGerald and coworkers investigated the mechanisms by which COX-2 
inhibitors increase the risk of myocardial infarction. Their studies demonstrated that selective inhibition, knockout, or mutation of COX-2, or deletion of the receptor for COX-2 derived $\mathrm{PGI}_{2}$, was shown to accelerate thrombogenesis and elevate blood pressure in mice. These responses were attenuated by COX-1 knock down, which mimics the beneficial effects of low-dose aspirin. In addition, these authors suggest that inhibitors of microsomal PGE synthase-1 (mPGES-1) may exhibit efficient anti-inflammatory activity with no adverse cardiovascular events (60).

\subsection{COX and cancer}

Several reports, over a period of many years, have shown that traditional NSAIDs exhibit anticancer activities. For example, sulindac and indomethacin exhibit protective effects against colorectal cancer (61). After the discovery of the COX-2 isoform, several studies have shown that COX-2 is expressed at high levels in a wide variety of cancer tissues, such as colon, breast, prostate and pancreas and appears to control many cellular processes. Selective COX-2 inhibitors have been extensively studied in the treatment and prevention of a variety of cancers $(10,62)$. The anticancer activity exhibited by NSAIDs and selective COX-2 inhibitors could be associated with multiple COXdependent and COX-independent pathways $(63,64)$. The selective COX-2 inhibitor celecoxib induces apoptosis in human prostate cancer cell lines (PC-3) expressing COX-2 by blocking antiapoptotic kinase Akt activation, and the antiangiogenic activity of COX-2 inhibitors may constitute another mechanism to prevent tumor growth $(65,66)$. Celebrex is currently available as a pharmacological adjunct in the management of familial adenomatous polyposis (FAP). In contrast, the eighteen month adenomatous polyp prevention Vioxx ${ }^{\circledR}$ (APPROVe) trial, where the efficacy of rofecoxib in preventing the recurrence of colon polyps was investigated was stopped early because of an increase in adverse cardiovascular events (67). This latter study has put a shadow of doubt on the long term use of selective COX-2 inhibitors in chemoprevention.

\subsection{COX and the central nervous system (CNS)}

The use of NSAIDs has been associated with a delay in the onset of Alzheimer's disease (AD) in high risk families (68). Since AD is associated with inflammatory conditions in brain, the protective effect provided by NSAIDs is consistent with their anti-inflammatory activity. Initially, selective COX2 inhibitors were touted as a potential therapy to treat AD since long term treatment using NSAIDs leads to GI toxicity (69). However, current data regarding the use of selective COX-2 inhibitors in $\mathrm{AD}$ is conflicting. For example, a recent study has shown that the selective COX-2 inhibitor rofecoxib failed to slow cognitive decline in patients with mild-to-moderate $\mathrm{AD}$ (70). In contrast, a recent investigation showed that cyclooxygenase-2 inhibition improves $\beta$-amyloid mediated suppression of memory and synaptic plasticity. This suggests that selective COX-2 inhibitors may protect against $\mathrm{AD}$ by blocking the COX-2mediated $\mathrm{PGE}_{2}$ response at synapses (71). However, the long term cardiovascular toxicities associated with selective COX-2 inhibitor therapy makes their application in AD questionable (72). Parkinson's disease (PD) is a neurodegenerative disease wherein loss of dopaminergic transmission leads to rigidity, resting tremors and slowness of movement ultimately leading to death. Since PD progression has an inflammatory pathology, studies on mice deficient with COX-2 exhibited resistance in animal models of PD. These results showed that COX-2 plays an important role in animal models of dopaminergic neuron degeneration (73). A recent report by Pzedborwski and coworkers described the pathological role of COX-2 in the development of PD. This study examined the role of increased levels of COX-2 in generating a toxic dopaminequinone species which was responsible for dopaminergic neuronal degeneration. The selective COX-2 inhibitor rofecoxib exhibited a neuroprotective effect. Other studies have also shown that the selective COX-2 inhibitor paracoxib exhibits neuroprotective activity in animal models of PD $(74,75)$.

\subsection{COX-3}

A new twist was added to the COX story in 2002 with the discovery of a third isoform COX-3 by Simmons and coworkers (76). Their study in dogs showed that COX-3 was present as an alternative splice variant of COX-1. 


\section{MOLECULAR BASIS OF COX INHIBITION}

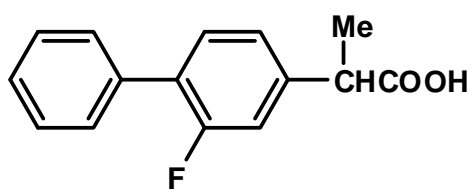

Fluorbiprofen (5)

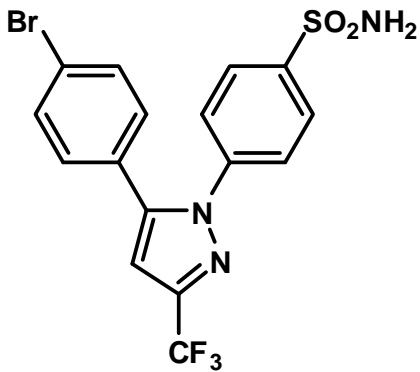

SC-558 (6)
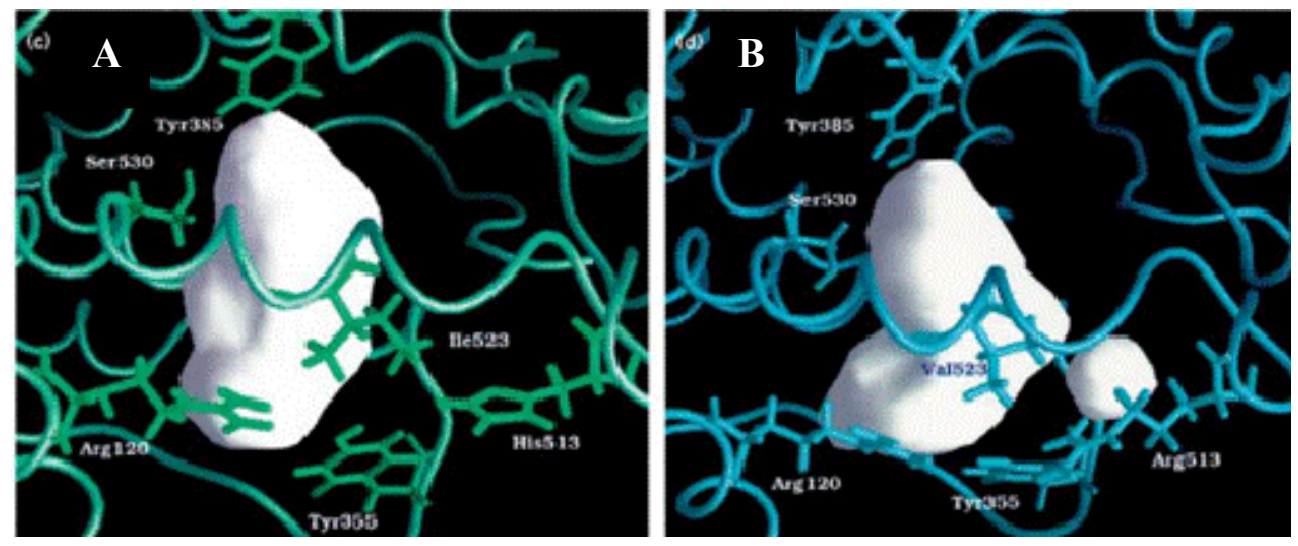

Figure 4. A. Active site of COX-1. B. Active site of COX-2 [adapted by permission from Macmillan Publishers Ltd: (Nat. Struct. Biol. Vol: 3, 1996, ref 80).

It was long suspected that the widely used over-thecounter analgesic/antipyretic agent acetaminophen acts by inhibiting a brain specific COX isoform (77). Acetaminophen, unlike other NSAIDs, is known to exhibit weak inhibition of both COX-1 and COX-2 at therapeutic concentrations. The Simmons group showed that indeed COX-3 was the target of acetaminophen. However, the initial excitement surrounding the discovery of COX-3 as a potential drug target received a reality check when it was discovered that one can not generalize the presence of canine COX-3 to humans. It is now known that COX-3 encodes proteins with completely different amino acid sequences than COX-1 or COX-2 in rodents and humans and moreover lacks COX activity. This negates its role in causing pain and fever. Therefore, the clinical relevance of COX-3 as a drug target is questionable. However the final jury on this question is not out yet $(78,79)$.

Although NSAIDs were known to inhibit the COX enzyme to produce their antiinflammatory and analgesic activities, a clear structural insight regarding the binding modes of NSAIDs was not available until 1994. Garavito and coworkers published a landmark paper that described the crystal structure of COX-1 complexed with the NSAID fluorbiprofen 5 (32). This study showed that the COX-1 active site consists of a 
long, hydrophobic, narrow channel extending from the membrane binding domain all the way to the center of the COX monomer. The apex of the COX active site was comprised of Tyr385 that sits near heme iron. The aspirin acetylation site, Ser530, is positioned below Tyr385. The mouth of the COX-1 channel was comprised of polar residues such as Arg120 and Glu524. The carboxylate moiety of $\mathbf{5}$ was oriented toward the mouth of the COX active site where it is in a favorable position to interact with polar residues (Arg120 and Glu524). This structure study gave mechanistic insight into the binding modes of NSAIDs. Shortly thereafter, the crystal structures of human and murine COX-2 complexed with selective COX-2 inhibitors were solved $(80,81)$. These studies confirmed the belief that the COX isoforms are structurally homologous and quite super imposable.

The interactions of NSAIDs within the COX active sites have been studied extensively. Most traditional NSAIDs are nonselective inhibitors of both isoforms whereas selective COX-2 inhibitors exhibit tight binding to the COX-2 active site. Traditional NSAIDs exhibit one of three different modes of binding: i) reversible binding (eg: ibuprofen), ii) rapid, low affinity reversible binding followed by a time-dependent, higher affinity, slowly reversible binding (eg: fluorbiprofen, 5), iii) or a rapid, reversible binding followed by a covalent modification of the enzyme (eg: aspirin). Selective COX-2 inhibitors exhibit time-dependent inhibition of COX-2 but not COX-1. At the entrance of the COX channel, Arg120, Glu524, Tyr355 and His90 form a network of hydrogen bonds that act as a gate to the binding site (82). NSAIDs generally bind between the upper portion of the COX channel located near Tyr385 and $\operatorname{Arg} 120$ which is present at the mouth of the COX channel.

The carboxyl moiety of acidic NSAIDs such as fluorbiprofin (5) interacts with Arg120 in both COX isoforms, via hydrogen bonding or electrostatic interactions (83). The remaining ligand-protein interaction is hydrophobic. Crucial structural differences within the binding sites of the COX isoforms have been exploited to design selective COX-2 inhibitors. In the COX-2 active site, due to the presence of a smaller valine at amino acid residue at position 523 (isoleucine in COX-1) and a valine (isoleucine in COX-1) subsitution at position 434 creates an extra pocket (secondary pocket) which is accessible in the COX2 active site. This difference increases the overall volume of the COX-2 active site $\left(394 \AA^{3}\right)$ by almost $20 \%$ compared to that of COX-1 (316 $\AA^{3}$, Figure 4$)$. Thus, nonacidic selective COX-2 inhibitors can show enhanced binding to COX-2 due to reduced steric and ionic crowding at the mouth of the channel (binding site) by Arg120. Other structural differences exist at amino acid residue 513 where COX-1 has a histidine (His) residue and COX-2 has an arginine (Arg) moiety. These subtle differences provide substrate flexibility in the COX-2 active site. The crystal structure of the diarylheterocyclic selective COX-2 inhibitor SC-558 6 (81) firmly established the structural basis for the COX-2 selectivity exhibited by this class of compounds (Figure 5).

The para- $\mathrm{SO}_{2} \mathrm{NH}_{2}$ pharmacophore of the 1,5-diarylpyrazole (SC-558, 6) plays a crucial role in COX-2 selectivity by insertion into the COX-2 secondary pocket where it undergoes favorable interactions with amino acid residues lining the secondary pocket such as His90, Arg513, Phe518 and Gln192 within the COX-2 active site. The C-5 para-bromophenyl ring of $\mathrm{SC}-558$ is oriented toward the top (apex) of the COX-2 active site where it is positioned to undergo hydrophobic contacts with Phe381, Tyr385, Phe513, Trp387 and Leu384. The $\mathrm{CF}_{3}$ group at the 3-position of the central pyrazole ring binds to a hydrophobic pocket consisting of Met113, Val116, Val349, Tyr355, Leu359 and Leu531. This crystal structure showed the importance of pharmacophores such as a $\mathrm{SO}_{2} \mathrm{NH}_{2}$, or a $\mathrm{SO}_{2} \mathrm{Me}$, substituent at the paraposition of one of the phenyl rings in the design of diarylheterocyclic or diarylcarbocyclic selective COX-2 inhibitors (81).

In vitro evaluation of NSAIDs and selective COX-2 inhibitors have been tested using numerous assay systems. Based on $\mathrm{IC}_{50}$ values for both the COX-1 and COX-2 isoforms, COX-2 selectivity (ratio of COX-1 $\mathrm{IC}_{50} / \mathrm{COX}-2 \quad \mathrm{IC}_{50}=$ Selectivity Index; SI) has been derived, which can be used to compare COX inhibition and selectivity data for diverse classes of COX inhibitors. Some examples of in vitro COX inhibition assay systems utilize purified/recombinant enzymes, or various cell lines obtained from either human or animal sources (84, $85)$. 


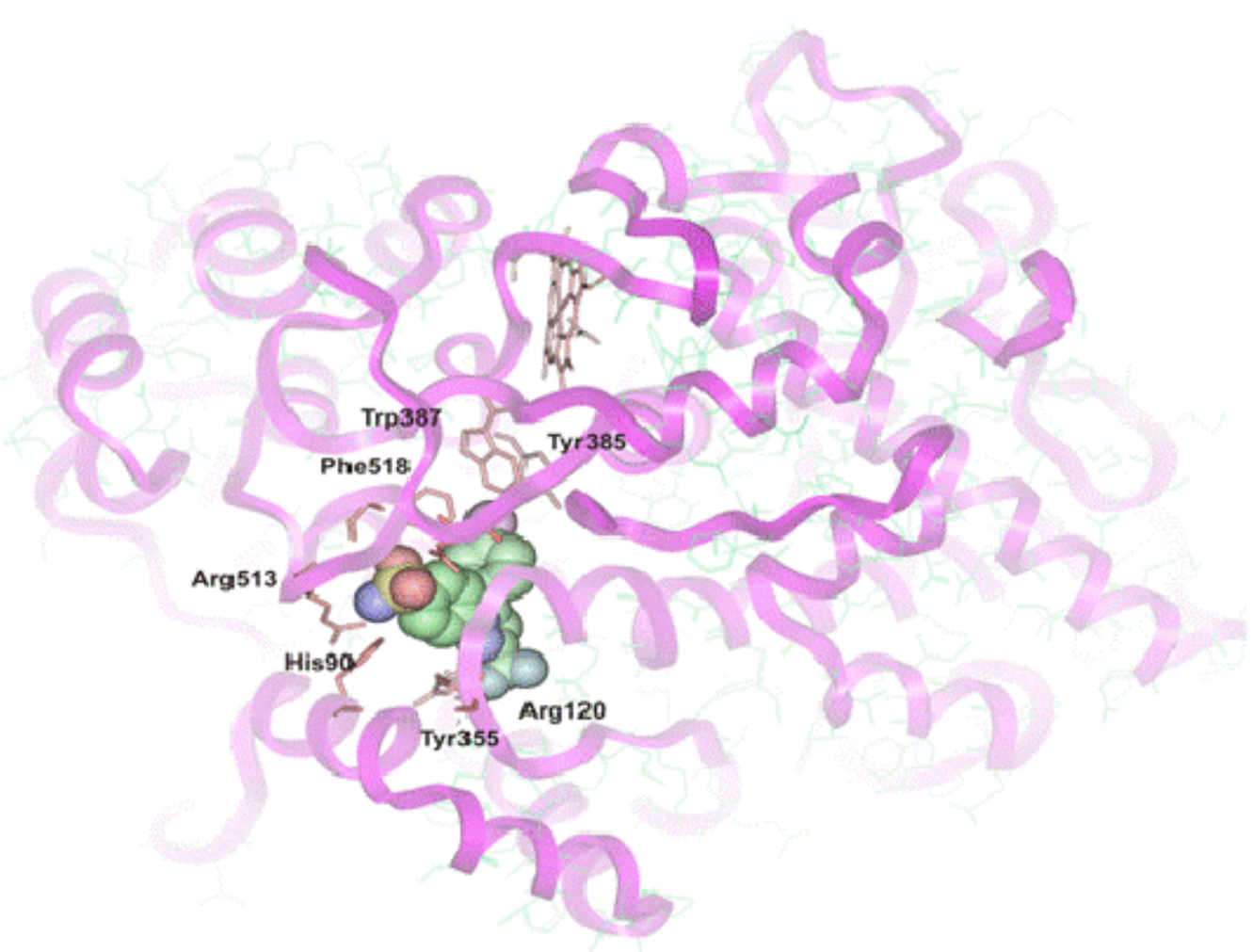

Figure 5. The ribbon diagram of the murine COX-2 enzyme with the diaryheterocyclic selective COX-2 inhibitor SC-558 (represented as space filling model) bound to the COX-2 active site (ref 81).

\section{COX ASSAYS, INHIBITORY POTENCY AND COX ISOZYME SELECTIVITY}

Table 2. Classification of NSAIDs according to their COX-1/2 inhibitory activities.

\begin{tabular}{|c|c|c|}
\hline Class & Properties & Examples \\
\hline Group 1 & $\begin{array}{l}\text { NSAIDs that inhibit both COX-1 and COX-2 } \\
\text { completely with little selectivity }\end{array}$ & $\begin{array}{l}\text { Aspirin, ibuprofen, diclofenac, } \\
\text { indomethacin, naproxen, piroxicam }\end{array}$ \\
\hline Group 2 & $\begin{array}{l}\text { NSAIDs that inhibit COX-2 with a 5-50 fold } \\
\text { selectivity }\end{array}$ & $\begin{array}{l}\text { Celecoxib, etodolac, meloxicam, } \\
\text { nimesulide }\end{array}$ \\
\hline Group 3 & $\begin{array}{l}\text { NSAIDs that inhibit COX-2 with a }>50 \text { fold } \\
\text { selectivity }\end{array}$ & Rofecoxib, NS-398 \\
\hline Group 4 & $\begin{array}{l}\text { NSAIDs that are weak inhibitors of both } \\
\text { isoforms }\end{array}$ & $\begin{array}{l}\text { 5-Aminosalicylic acid, sodium } \\
\text { salicylate, nabumetone, sulfasalazine }\end{array}$ \\
\hline
\end{tabular}

Each of these assay systems have their benefits and drawbacks. Based on the aim of the experiment, one can carefully select the most appropriate in vitro assay system. For example, if the aim is to understand the enzyme-drug interaction at the molecular level, then purified or recombinant 
enzyme systems are used. NSAIDs exhibit strong binding to plasma proteins. Therefore, an in vitro purified enzyme assay system is not suited to study the plasma concentration of the drug to predict its in vivo activity. In contrast, human whole blood assays can be used to assess the in vivo plasma concentrations since intact cells are used that account for cell permeability and plasma protein binding of drugs. Vane and coworkers classified NSAIDs based on the COX inhibition and selectivity data obtained using a human modified whole blood assay (WHMA) as shown in Table 2 (86). COX-1/2 inhibition data and COX-2 selectivity's for NSAIDs including their clinical dose for treating RA and $\mathrm{OA}$ is summarized in Table $3(86,87,88)$.

\section{CHEMICAL CLASSIFICATION OF SELECTIVE COX-2 INHIBITORS}

\subsection{Methanesulfonanilide inhibitors}

Members of the methanesulfonanilide class of COX-2 inhibitors generally exhibit preferential COX-2 selectivity (COX-2 selectivity between 5-50, Table 2). These compounds are characterized as derivatives of alkylsulfonanilides (Figure 6). Nimesulide (7) was the first member of this class to be discovered. Pharmacological studies demonstrating nimesulide's clinical antiinflammatory properties have been reported (89). Structural modification of nimesulide culminated in the development of NS-398 (8) with better COX-2 selectivity and anti-inflammatory activity (90).

Table 3. NSAID COX-1/2 inhibitory potencies and selectivities determined using a whole blood assay and their clinical dose to treat RA and OA.

\begin{tabular}{|c|c|c|c|c|c|c|}
\hline \multirow[t]{2}{*}{ Drug } & \multirow[t]{2}{*}{ Trade name } & \multicolumn{2}{|c|}{ Whole blood assay $\mathrm{IC}_{50}(\mu \mathrm{M})$} & \multirow{2}{*}{$\begin{array}{l}\text { Selectivity } \\
\text { Index }\end{array}$} & \multicolumn{2}{|c|}{ Clinical dose (mg) } \\
\hline & & COX-1 & COX-2 & & RA & OA \\
\hline Aspirin & $\begin{array}{l}\text { Aspirin }{ }^{\circledR} \\
\text { Ecotrin }{ }^{\circledR}\end{array}$ & 1.7 & $>100$ & 0.017 & $2600-3900$ & - \\
\hline Diclofenac & Voltaren ${ }^{\circledR}$ & 0.075 & 0.038 & 1.97 & $150-200$ & $100-150$ \\
\hline $\begin{array}{l}\text { Ibuprofen } \\
\text { Motrin } \AA\end{array}$ & Advil@ & 7.6 & 7.2 & 1.05 & $1200-3200$ & $1200-3200$ \\
\hline Indomethacin & Indocin $\mathbb{R}$ & 0.013 & 1.0 & 0.013 & $150-200$ & $150-200$ \\
\hline Ketoprofen & Orudis $\AA$ & 0.047 & 2.9 & 0.016 & $200-300$ & $200-300$ \\
\hline Fluorbiprofen & $\begin{array}{l}\text { Fluorbiprofen }{ }^{\circledR} \\
\text { Ansaid } \AA\end{array}$ & 0.075 & 5.5 & 0.013 & $200-300$ & $200-300$ \\
\hline Naproxen & $\begin{array}{l}\text { Naprosyn }{ }^{\circledR} \\
\text { Aleve }{ }^{\circledR}\end{array}$ & 9.3 & 28 & 0.33 & $500-1000$ & $500-1000$ \\
\hline Nimesulide & Mesulid $\AA$ & 10 & 1.9 & 5.26 & - & 200 \\
\hline Meloxicam & Mobic $\mathbb{R}$ & 5.7 & 2.1 & 2.7 & $7.5-15$ & $7.5-15$ \\
\hline Paracetamol & Tylenol $®$ & $>100$ & 49 & $>2.04$ & $2600-4000$ & $2600-4000$ \\
\hline Celecoxib & Celebrex ${ }^{\circledR}$ & 6.7 & 0.87 & 7.7 & $200-400$ & 200 \\
\hline Valdecoxib & Bextra ${ }^{\circledR}$ & 26 & 0.87 & 29.8 & 10 & 10 \\
\hline Rofecoxib & Vioxx $®$ & 19 & 0.53 & 35.8 & 25 & $12.5-25$ \\
\hline Etoricoxib & $\operatorname{Arcoxia}{ }^{\circledR}$ & 116 & 1.1 & 105.4 & 90 & 60 \\
\hline Lumiracoxib & Prexige $\AA$ & 67 & 0.13 & 515 & - & $200-400$ \\
\hline
\end{tabular}


<smiles>COS(=O)(=O)c1ccc([N+](=O)[O-])cc1Oc1ccccc1</smiles>

Nimesulide (7)<smiles>COS(=O)(=O)c1ccc([N+](=O)[O-])cc1OC1CCCCC1</smiles>

NS-398 (8)<smiles>O=C1C(Cc2ccccc2)C(=O)N(c2ccccc2)N1c1ccccc1</smiles>

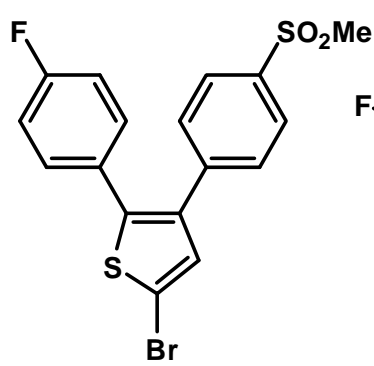

DuP-697(10)<smiles>COS(=O)(=O)c1ccc(C2=C(c3ccc(F)cc3)CCC2)cc1</smiles>

SC-57666 (11)<smiles>NS(=O)(=O)c1ccc(C2=C(c3ccc(F)cc3)CCC2)cc1</smiles>

(12)

Figure 6. Chemical structures of some COX inhibitors

\subsubsection{Diarylheterocycles as selective $\mathrm{COX}-2$ inhibitors}

The majority of selective COX-2 inhibitors are diarylheterocycles. The historical origins of diarylheterocycles as pharmacophores can be traced back to the anti-inflammatory agent phenylbutazone 9 (Figure 6) which stimulated medicinal chemists worldwide to further explore diarylheterocycles. In this regard, researchers at DuPont initiated an extensive program in the 1970's to evaluate novel diarylheterocycles as anti-inflammatory agents which led to the discovery of a very potent and selective COX-2 inhibitor DuP-697 10 possessing a central 5-membered thiophene ring (Figure 6). A common structural feature of these tricyclic molecules is the presence of 1,2-diaryl substitution on a central 5-membered ring system. Structureactivity relationship (SAR) studies have shown that for optimum $\mathrm{COX}-2$ selectivity and inhibitory potency a $-\mathrm{SO}_{2} \mathrm{Me}$, or a $-\mathrm{SO}_{2} \mathrm{NH}_{2}$ substituent at the para-position of a phenyl ring was essential, and that the presence of a para-F-substituent on the non-sulfonyl vicinal phenyl ring often improves in vivo activity (89).

The 2,3-diphenylthiophene $\mathbf{1 0}$ (Figure 6) exhibited excellent COX-2 inhibitory potency and selectivity $\left(\mathrm{COX}-2 \mathrm{IC}_{50}=0.01 \mu \mathrm{M}, \mathrm{COX}-1 \mathrm{IC}_{50}=\right.$ $1 \mu \mathrm{M}$; SI = 100). However, this drug failed in the clinic due to an unusually long plasma half life (89). Replacement of the bromine atom on the central thiophene provided compounds with better pharmacokinetic profiles (91). Generally, for this class of diarylheterocycles, the presence of a para$\mathrm{SO}_{2} \mathrm{NH}_{2}$ moiety resulted in increased COX-2 inhibitory potency and improved oral absorption $(92,93)$. In the design of selective COX-2 inhibitors various types of tricyclic diarylcarbocycles have been evaluated extensively. Examples include diarylcarbocycles with a central 4-membered cyclobutene or cyclobutenone, a 5-membered cyclopentene or cyclopetenone, and a 6-membered aromatic ring such as benzene (89). Diphenylcyclopentenes and cyclopentenones were among the first series of compounds to be evaluated for COX-2 selectivity and potency (89). Searle scientists reported that the diarylcyclopentene SC5766611 (Figure 6) exhibited a very high degree of in vitro COX-2 inhibitory potency and selectivity. In vivo anti-inflammatory activity assays showed 11 was effective and no gastric complications were observed (94). Replacement of the para- $\mathrm{SO}_{2} \mathrm{Me}$ moiety present in $\mathbf{1 1}$ by a para- $\mathrm{SO}_{2} \mathrm{NH}_{2}$ moiety as in 12 improved oral bioavailability. This review will focus on the tricyclic class of selective COX-2 inhibitors possessing either a 5- or 6-membered heterocyclic central ring scaffold (template). 


\subsubsection{Diarylheterocycles with a central 5-membered pyrazole ring}<smiles>N#Cc1cc(-c2ccc(F)cc2)n(-c2ccc(I)cc2)n1</smiles>

(13)

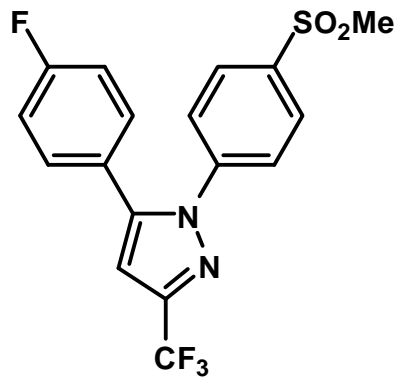

SC52185 (14)

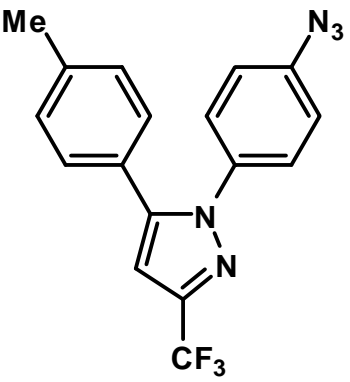

(15)

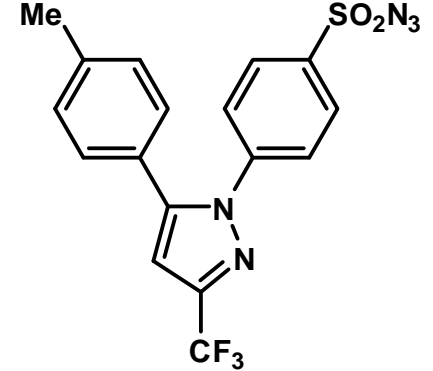

(16)

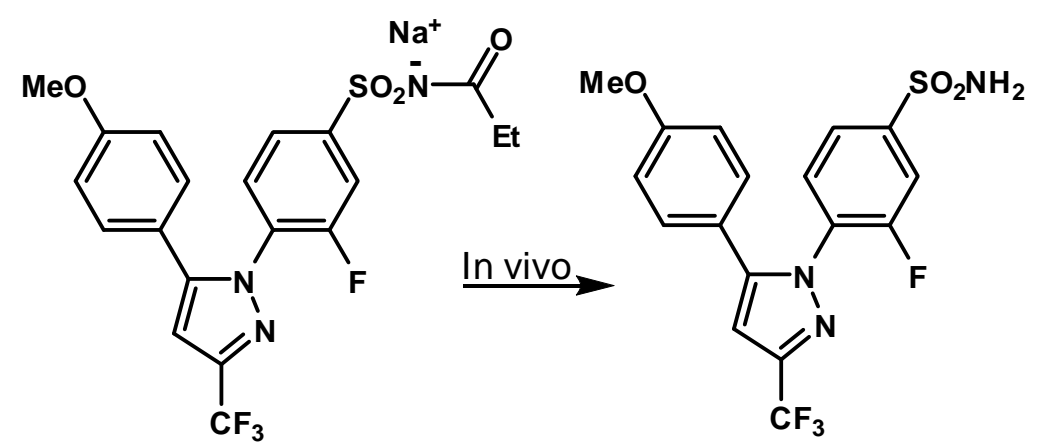

(17)

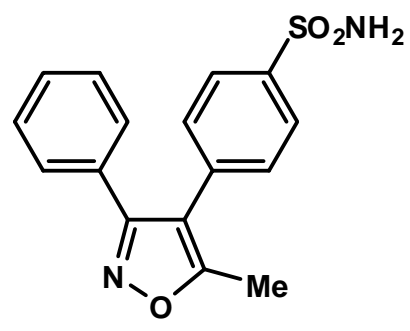

Valdecoxib (20)

(18)

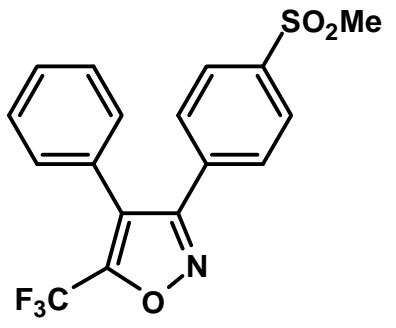

(21)

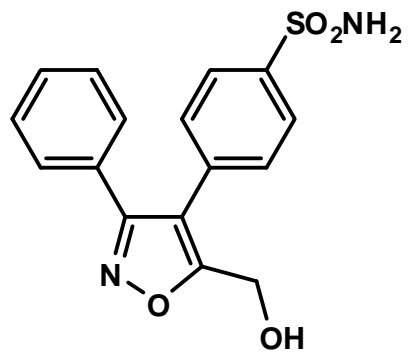

(19)

Figure 7. Chemical structures of tricyclic selective COX-2 inhibitors possessing a central 5-membered pyrazole or isoxazole ring.

The 1,5-diarylpyrazole class of compounds (Figure 7) proved to be a fertile source for highly potent and selective COX-2 inhibitors. The first compound (13) examined in this series exhibited excellent in vitro COX-2 inhibitory potency and selectivity (COX-2 $\left.\mathrm{IC}_{50}=0.24 \mu \mathrm{M}, \mathrm{COX}-1 \quad \mathrm{IC}_{50}>100 \mu \mathrm{M} ; \mathrm{SI}>417\right)$ with potent anti-inflammatory activity in animal models with no tendency to cause GI damage (89). During the initial stage of the development of the 1,5-diarylpyrazole class of selective COX-2 inhibitors, SC-58125 (14) was one of the most extensively characterized compounds (45). Compound $\mathbf{1 4}$ possessed a very long in vivo half life of $>200$ hours in animal models making it unacceptable for clinical use. Replacement of the para- $\mathrm{SO}_{2} \mathrm{Me}$ group by a $\mathrm{SO}_{2} \mathrm{NH}_{2}$ substituent provided a significant improvement in the pharmacological profile. Compounds of this type exhibited superior pharmacological and oral bioavailability than their methylsulfone $\left(\mathrm{MeSO}_{2}\right)$ 
counterparts. Extensive studies within this class of compounds led to the successful development of the potent and selective COX-2 inhibitor SC-58635 (3) (in vitro COX-2 $\mathrm{IC}_{50}=0.04 \mu \mathrm{M} ; \mathrm{COX}-1 \mathrm{IC}_{50}=13$ $\mu \mathrm{M} ; \quad$ SI $=325$ ) with potent in vivo antiinflammatory activity. Compound $\mathbf{3}$ was selected for clinical evaluation and subsequent introduction to the market as celecoxib (Celebrex ${ }^{\circledR}$ ), the first diarylheterocyclic selective COX-2 inhibitor approved for clinical use (12).

In an elegant study, Knaus and coworkers showed that the para- $\mathrm{SO}_{2} \mathrm{NH}_{2}$ pharmacophore in celecoxib and the para- $\mathrm{SO}_{2} \mathrm{Me}$ pharmacophore in rofecoxib can be replaced by a linear azide $\left(\mathrm{N}_{3}\right)$ or a sulfonyl azido group. This was the first example where a crucial binding site structural difference in COX-1 and COX-2 was exploited $(95,96)$. Replacement of His513 in COX-1 by Arg513 in COX-2 has been reported to play a key role in the hydrogen-bond network of the COX active site (97). Molecular modeling studies indicated that azide and sulfonyl azide groups were undergoing electrostatic interactions with the polar Arg513 residue within the COX-2 active site. The azido compound $\mathbf{1 5}$ (Figure 7) exhibited good COX-2 inhibitory potency/selectivity (COX-2 IC $_{50}=1.55 \mu \mathrm{M}, \mathrm{COX}-1$ $\mathrm{IC}_{50}>100 \mu \mathrm{M}$; SI $\left.>64.5\right)$ in conjunction with in vivo activity. In contrast, the sulfonylazido compound $\mathbf{1 6}$ did not inhibit the COX-2 isoform at $100 \mu \mathrm{M}$ indicating the subtle requirements needed for COX-2 binding.

Celecoxib is a highly lipophilic water insoluble drug that is administered orally. A recent investigation demonstrated that one can develop parenteral (water soluble) formulations of selective COX-2 inhibitors that possess a central pyrazole ring (98). For example, the water soluble sodium salt of the $N$-propionylsulfonamide compound $\mathbf{1 7}$ is a weak COX-2 inhibitor that is a prodrug which is converted to the respective sulfonamide compound (18) in vivo. The sulfonamide compound $\mathbf{1 8}$ exhibits good COX-2 inhibitory potency and selectivity $\left(\mathrm{COX}-2 \mathrm{IC}_{50}=1.7 \mu \mathrm{M}\right.$; COX $-1 \quad \mathrm{IC}_{50}>$ 100; SI > 59). Selective COX-2 inhibitors belonging to the 1,5-diarylpyrazole class are still being pursued (99).

\subsubsection{Diarylheterocycles possessing a central 5- membered isoxazole ring}

A large number of regioisomeric diarylisoxazoles have been evaluated as selective COX-2 inhibitors. Scientists at Searle reported that the isoxazole 19 (Figure 7) is a potent and selective $\mathrm{COX}-2$ inhibitor $\left(\mathrm{COX}-2 \mathrm{IC}_{50}=0.18 \mu \mathrm{M}, \mathrm{COX}-1 \mathrm{IC}_{50}>1000 \mu \mathrm{M}\right.$; SI $>5555)$ that shows an excellent in vivo activity profile (89). Lead optimization with the diarylisoxazole class of compounds culminated in the development of a potent and selective COX-2 inhibitor which had a para- $\mathrm{SO}_{2} \mathrm{NH}_{2}$ substituent (Valdecoxib, 20, COX-2 IC $_{50}=0.005 \mu \mathrm{M}, \mathrm{COX}-1$ $\left.\mathrm{IC}_{50}=140 \mu \mathrm{M} ; \quad \mathrm{SI}=28000\right)$. The 5-methyl substituent in Valdecoxib (20) undergoes bioconversion in an in vivo rodent model to the active 5-hydroxymethyl $\left(\mathrm{CH}_{2} \mathrm{OH}\right)$ metabolite 19. Low levels of the hydroxymethyl metabolite $\mathbf{1 9}$ has also been detected in humans (100). The isoxazole compound $\mathbf{2 0}$ (Figure 7) was marketed as valdecoxib (Bextra $\left.{ }^{\circledR}\right)$, a second generation selective COX-2 inhibitor with analgesic and antiinflammatory properties (101). Valdecoxib, like rofecoxib, was subsequently withdrawn from the clinical market. The water soluble prodrug of valdecoxib (Parecoxib sodium, Dynastat ${ }^{\circledR}$ ) was launched as an injectable COX-2 inhibitor possessing anti-inflammatory and analgesic activities (102).

In addition, Knaus and coworkers showed that regioisomeric 3,4-diarylisoxazoles with a para$\mathrm{SO}_{2} \mathrm{Me}$ substituents exhibit excellent in vitro COX2 inhibitory activity and in vivo anti-inflammatory activities (103). For example, the isoxazole regioisomer $\mathbf{2 1}$ is a potent and highly selective COX-2 inhibitor (COX-2 $\mathrm{IC}_{50}<0.005 \mu \mathrm{M}, \mathrm{COX}-1$ $\mathrm{IC}_{50}>500 \mu \mathrm{M}$; SI $\left.>100,000\right)$ that is marketed by Cayman Chemicals as a research biochemical. In contrast, the corresponding regioisomer 22 (Figure 7) was a less potent and selective $\mathrm{COX}-2$ inhibitor $\left(\mathrm{COX}-2 \mathrm{IC}_{50}=0.23 \mu \mathrm{M}, \mathrm{COX}-1 \mathrm{IC}_{50}=256 \mu \mathrm{M}\right.$; SI $=1113)$. 


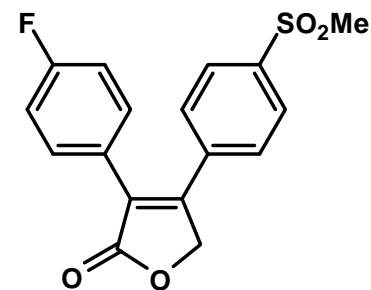

(23)<smiles>CC[C@]1(C)OC(=O)C(OC(C)C)=C1c1ccc(S(C)(=O)=O)cc1</smiles>

(26)

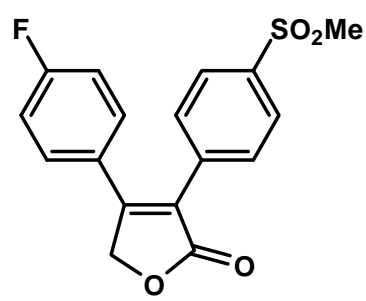

(24)

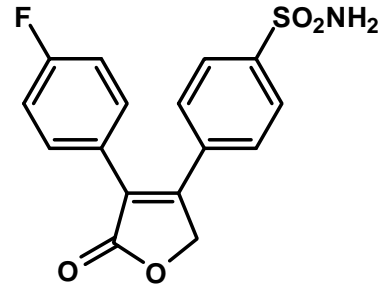

(25)

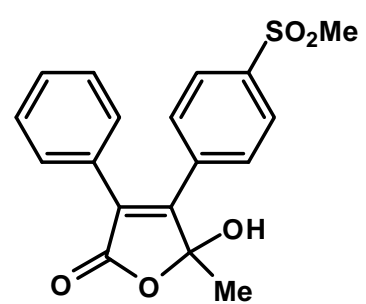

(27)

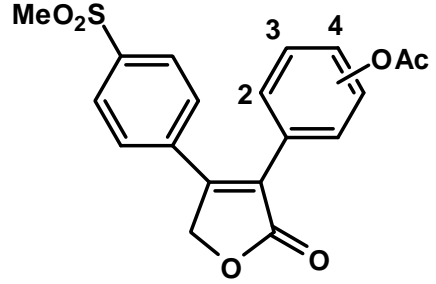

(28a-c)<smiles>COc1nc(-c2ccc(F)cc2)c(-c2ccc(S(C)(=O)=O)cc2)cc1C#N</smiles>

(29)<smiles>COc1cc(-c2ccc(S(C)(=O)=O)cc2)c(-c2ccc(F)cc2)c(C(F)(F)F)n1</smiles>

(30)
Etoricoxib (31)<smiles>COS(=O)(=O)c1ccc(-c2cnn(-c3ccccc3)c(=O)c2-c2ccccc2)cc1</smiles>

(32)<smiles>COS(=O)(=O)c1ccc(-c2cnn(Cc3ccccc3)c(=O)c2OC(C)C)cc1</smiles>

(33)

Figure 8. Chemical structures of tricyclic selective COX-2 inhibitors possessing a central 5-membered furanone, a 6membered pyridine, or pyridazinone ring.

\subsubsection{Diarylheterocycles with a central 5- membered furanone ring}

Extensive evaluation of the 3,4-diarylfuranone class of compounds indicated that compound 23 (Figure 8) was a selective COX-2 inhibitor $\left(\mathrm{COX}-2 \mathrm{IC}_{50}=\right.$ $\left.0.01 \mu \mathrm{M}, \mathrm{COX}-1 \mathrm{IC}_{50}>4.7 \mu \mathrm{M}\right)$ whereas, the regioisomer 24 was inactive. It is interesting to note that replacement of the para- $\mathrm{SO}_{2} \mathrm{Me}$ substituent present in 23 by a para- $\mathrm{SO}_{2} \mathrm{NH}_{2}$ substituent (25) resulted in a decreased COX-2 selectivity (COX-2 $\left.\mathrm{IC}_{50}=0.8 \mu \mathrm{M}, \mathrm{COX}-1 \mathrm{IC}_{50}=5.8 \mu \mathrm{M}\right)$. 
Further lead optimization by Merck and Co, led to the successful development and marketing of the highly selective and potent COX-2 inhibitor rofecoxib (4, Vioxx $\left.{ }^{\circledR}\right)$. Rofecoxib exhibited effective anti-inflammatory and analgesic activity with reduced GI toxicity and is a selective COX-2 inhibitor $\left(\mathrm{IC}_{50}=0.02 \mu \mathrm{M}, \mathrm{COX}-1 \mathrm{IC}_{50}>15 \mu \mathrm{M}\right.$; SI $>750$, ref 13,104$)$. Other variations in the $3,4-$ diarylfuranone class of compounds include the $(S)$ enantiomer of the 3-isopropoxy-5-ethyl-5-methyl derivative of rofecoxib (26, Figure 8) that possesses optimum COX-2 inhibitory and metabolic profiles (105). It was demonstrated that oral absorption of compounds belonging to the 3,4-diarylfuranone class can be increased by the introduction of a hydroxyl substituent at C-5 of the central furanone ring as observed for the 5-hydroxy compound $\mathbf{2 7}$ which retained its COX-2 selectivity $\left(\mathrm{COX}-2 \mathrm{IC}_{50}=\right.$ $0.16 \mu \mathrm{M}, \mathrm{COX}-1 \mathrm{IC}_{50}>100 \mu \mathrm{M}$, ref 106).

Aspirin 1 (Figure 1) is a unique nonselective COX inhibitor due to its ability to acetylate the serine hydroxyl group in the COX active sites of COX-1 and COX-2. Some of aspirin's beneficial therapeutic effects can be attributed to acetylation of $\mathrm{COX}-2$, while its antithrombotic and ulcerogenic effects are due to acetylation of COX-1. Knaus and coworkers designed and synthesized a group of isomeric rofecoxib analogs possessing a 2-, 3- or 4-acetoxy moiety on the C-3 phenyl substituent of rofecoxib (28a-c, Figure 8), that exhibited highly potent and selective, COX-2 inhibitory activity $\left(\mathrm{COX}-2 \mathrm{IC}_{50}=\right.$ 1.3 to $3.5 \mathrm{nM}$ range; COX-1 $\mathrm{IC}_{50}>100 \mu \mathrm{M}$, ref 107). Molecular modeling studies indicated that the acetyl groups were suitably placed to effect acetylation of Ser530 in the COX-2 binding site (Figure 9).

\subsubsection{Diarylheterocycles with a central 6- membered pyridine ring}

Tricycles with either a 2,3-diarylpyridine or 3,4diarylpyridine ring system have been investigated as selective COX-2 inhibitors wherein compounds 29 and $\mathbf{3 0}$ exhibited good in vitro COX-2 selectivity profiles. However, compounds $\mathbf{2 9}$ and $\mathbf{3 0}$ exhibited poor in vivo anti-inflammatory activities $(89,108)$. From this novel class of compounds, Merck and Co successfully developed the orally active potent and selective COX-2 inhibitor etoricoxib (31, Arcoxia $\left.{ }^{\circledR}\right)$ which exhibited clinically acceptable antiinflammatory and analgesic activity with no reports of gastric damage in animal studies and during clinical trials. This second generation selective COX-2 inhibitor showed an in vitro $\mathrm{COX}-2 \mathrm{IC}_{50}=$ $0.08 \mu \mathrm{M}$ and COX-1 $\mathrm{IC}_{50}=12 \mu \mathrm{M}$; SI $=150(87$, 108). Although etoricoxib is not an approved drug in the US and Canada due to its cardiovascular toxicity, it has been approved and is marketed in 63 other countries. A recent study assessed the cardiovascular outcomes of etoricoxib in comparison with diclofenac. These studies suggested that both drugs carry similar cardiovascular risks (109).

\subsubsection{Diarylheterocycles with a central 6- membered pyridazinone ring}

Recent studies have shown that the pyridazinone ring can serve as excellent core template for designing selective COX-2 inhibitors (Figure 8). Structure activity relationship studies (SAR) employing pyridazinones have shown that $\mathrm{N}$ substitution is a requirement for $\mathrm{COX}-2$ selectivity as exemplified by 32 (in vitro COX-2 $\mathrm{IC}_{50}=0.08$ $\mu \mathrm{M}$; COX-1 $\left.\mathrm{IC}_{50}>10 \mu \mathrm{M}\right)$. In the $N$-benzyl series, the isopropoxy compound $\mathbf{3 3}$ showed excellent in vitro selective $\mathrm{COX}-2$ inhibition $\left(\mathrm{COX}-2 \mathrm{IC}_{50}=\right.$ $0.02 \mu \mathrm{M}$; COX-1 $\mathrm{IC}_{50}>10 \mu \mathrm{M}$; SI $\left.>500\right)$ and in vivo activity (110).

\subsubsection{Diarylheterocycles with a central 6- membered pyranone ring}

The tricyclic class of compounds with a central six-membered lactone (pyran-2-one) serve as an excellent ring template for the design of selective COX-2 inhibitors (Figure 10). For example, Knaus and coworkers designed a group of 3,4-diphenylpyran-2-ones possessing a central sixmembered lactone ring (111). The lactone 34 was a potent and selective COX-2 inhibitor $\left(\mathrm{COX}-2 \mathrm{IC}_{50}\right.$ $=3 \mathrm{nM}$; COX-1 $\mathrm{IC}_{50}=386 \mu \mathrm{M} ; \mathrm{SI}=128666$ ).

In spite of its high COX-2 inhibitory potency and selectivity, 34 exhibited weak antiinflammatory activity in vivo. In contrast, the related lactone 35, exhibited good in vitro as well as in vivo activity (COX-2 $\mathrm{IC}_{50}=0.10 \mu \mathrm{M}$; COX-1 $\mathrm{IC}_{50}=288 \mu \mathrm{M}$; SI $=2880,68 \%$ inhibition of inflammation at a $1 \mathrm{mg} / \mathrm{kg}$ oral dose in a rat model). 


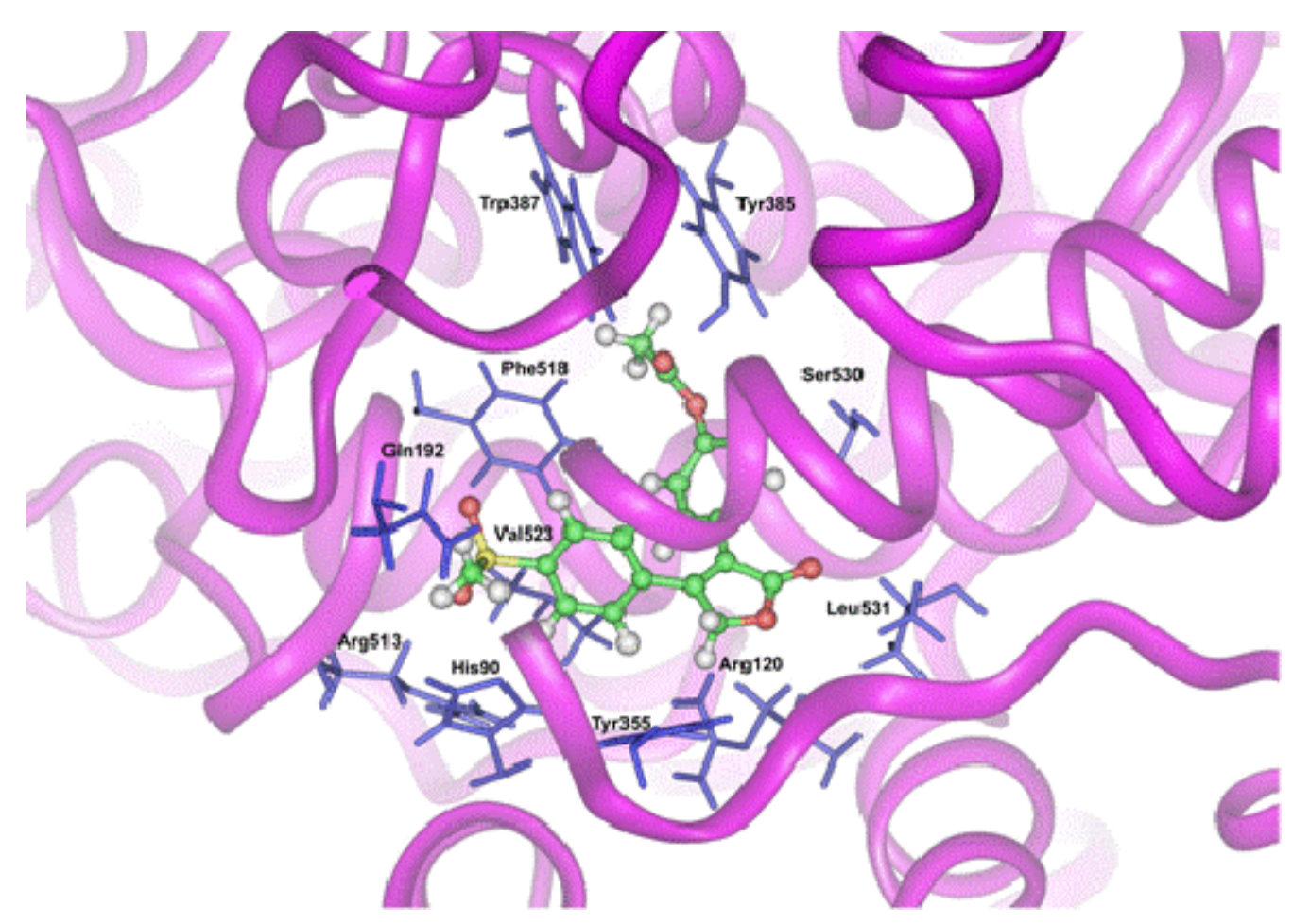

Figure 9. Docking of the rofecoxib analog (3-acetoxy regioisomer $\mathbf{2 8 b}$, ball and stick) in the active site of murine COX-2. The figure was generated according to a previously reported method (ref 112).

A molecular modeling study where the lactone $\mathbf{3 5}$ (Figure 11) was docked in the COX-2 binding site showed that the $\mathrm{COX}-2$ para- $\mathrm{SO}_{2} \mathrm{Me}$ pharmacophore was oriented favorably within the COX-2 active site where it interacted with amino acids lining the COX-2 secondary pocket (His90, Gln192, Arg513, Phe518, Val523 and Leu352). The central pyran-2-one ring was oriented toward the mouth of the channel (Tyr355 and Arg120). Interestingly, the C-6 ethoxy substituent was oriented toward a hydrophobic region comprised of Val349, Ile345, Ser530, Leu531 and Met535. These studies indicated that the orientation of the para$\mathrm{SO}_{2} \mathrm{Me}$ pharmacophore was dependent on the electronic and steric effects of the substituent present at the C- 6 position of the central pyran-2one ring.

An extension of this study showed that COX binding site was also able to accommodate C6 phenyl substituents resulting in the design of regioisomeric 3,4,6-triphenylpyrones as selective COX-2 inhibitors (112). Thus, the lactone 36 with a C-6 4-methoxyphenyl moiety (Figure 10) exhibited excellent $\mathrm{COX}-2$ inhibitory potency and selectivity $\left(\mathrm{COX}-2 \mathrm{IC}_{50}=0.02 \mu \mathrm{M}\right.$; COX-1 $\mathrm{IC}_{50}>100 \mu \mathrm{M}$;
SI > 5000). Compound 36 was 3.5 - and 25 -fold more potent than celecoxib $\left(\mathrm{COX}-2 \mathrm{IC}_{50}=0.07 \mu \mathrm{M}\right.$; $\mathrm{SI}=474)$ and rofecoxib $\left(\mathrm{COX}-2 \mathrm{IC}_{50}=0.50 \mu \mathrm{M}\right.$; SI $>200$ ), respectively. Although the corresponding regioisomer 37 exhibited good COX-2 inhibitory potency $\left(\mathrm{COX}-2 \mathrm{IC}_{50}=0.45 \mu \mathrm{M}\right.$; SI $\left.=70\right)$, it was less potent and selective than regioisomer $\mathbf{3 6}$. Among this group of compounds $\mathbf{3 8}$ having a C-6 4-ethoxyphenyl substituent exhibited good in vitro $\left(\mathrm{COX}-2 \mathrm{IC}_{50}=0.05 \mu \mathrm{M}\right.$; COX-1 $\left.\mathrm{IC}_{50}>100 \mu \mathrm{M}\right)$ and in vivo anti-inflammatory activity (61\% inhibition of inflammation at a $5 \mathrm{mg} / \mathrm{kg}$ oral dose in a rat model).

Joo and coworkers reported structurally related 2,3-diarylbenzopyran-4-ones (Figure 10) that exhibit potent in vitro COX-2 inhibitory potency and selectivity (113). Replacement of the para- $\mathrm{SO}_{2} \mathrm{Me}$ substituent in 39 by a para- $\mathrm{SO}_{2} \mathrm{NH}_{2}$ moiety provided compound $\mathbf{4 0}$ that showed increased in vitro COX-2 inhibitory potency and selectivity $\left(\mathrm{COX}-2 \mathrm{IC}_{50}=0.06 \mu \mathrm{M} ; \mathrm{COX}-1 \mathrm{IC}_{50}=\right.$ $67 \mu \mathrm{M})$. The introduction of a nitrogen containing aromatic ring, such as pyridine ring in $\mathbf{4 1}$, resulted in a better in vivo activity profile. 


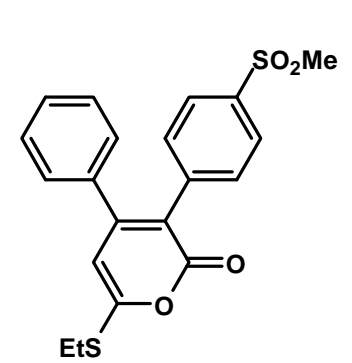

(34)

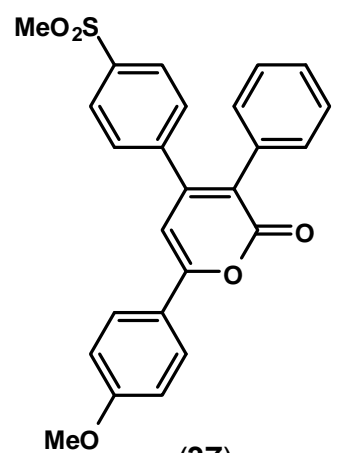

(37)

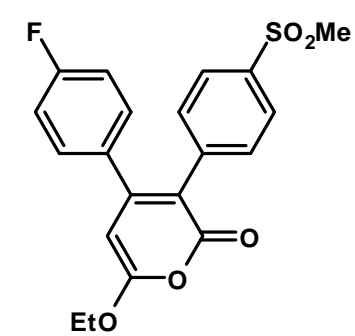

(35)<smiles>COc1ccc(-c2cc(-c3ccccc3)c(-c3ccc(S(C)(=O)=O)cc3)c(=O)o2)cc1</smiles><smiles>CCCCCCCCCCCOc1ccc(-c2cc(-c3ccccc3)c(-c3ccc(S(C)=O)cc3)c(=O)o2)cc1</smiles><smiles>CO[As](C)(=O)c1ccc(-c2oc3ccccc3c(=O)c2-c2ccc(F)cc2)cc1</smiles>

(39)<smiles>NS(=O)(=O)c1ccc(-c2oc3ccccc3c(=O)c2-c2ccc(F)cc2)cc1</smiles>

(40)<smiles>COS(=O)(=O)c1ccc(-c2oc3ccc(C(C)(F)F)cc3c(=O)c2-c2cccnc2)cc1</smiles>

(41)

Figure 10. Chemical structures of selective COX-2 inhibitors possessing a central 6-membered pyranone ring.

\subsection{ALTERNATIVE THERAPIES TO TREAT INFLAMMATORY CONDITIONS}

The adverse cardiovascular side effects associated with selective COX-2 inhibitors have highlighted the need to develop anti-inflammatory and analgesic agents that exhibit decreased GI side effects that are also devoid of adverse cardiovascular effects. Recent work by FitzGerald and coworkers suggest that microsomal PGE synthase-1 (mPGES-1) is an attractive target and that inhibitors of this enzyme may exhibit efficient anti-inflammatory activity with no adverse cardiovascular events (60). The major GI toxicity associated with NSAID therapy is well documented. In recent years many strategies have been developed to overcome the GI toxicities associated with NSAIDs. Nitric oxide ( $\mathrm{NO}$ ) is a biological molecule known to play a major role in a wide variety of physiological and pathological conditions (114). Some of its functions include vasodilation of blood vessels, GI mucosal healing and defense. Therefore NSAIDs containing NO-donor groups have been developed to obtain effective treatment of inflammation with reduced GI side effects (115). 


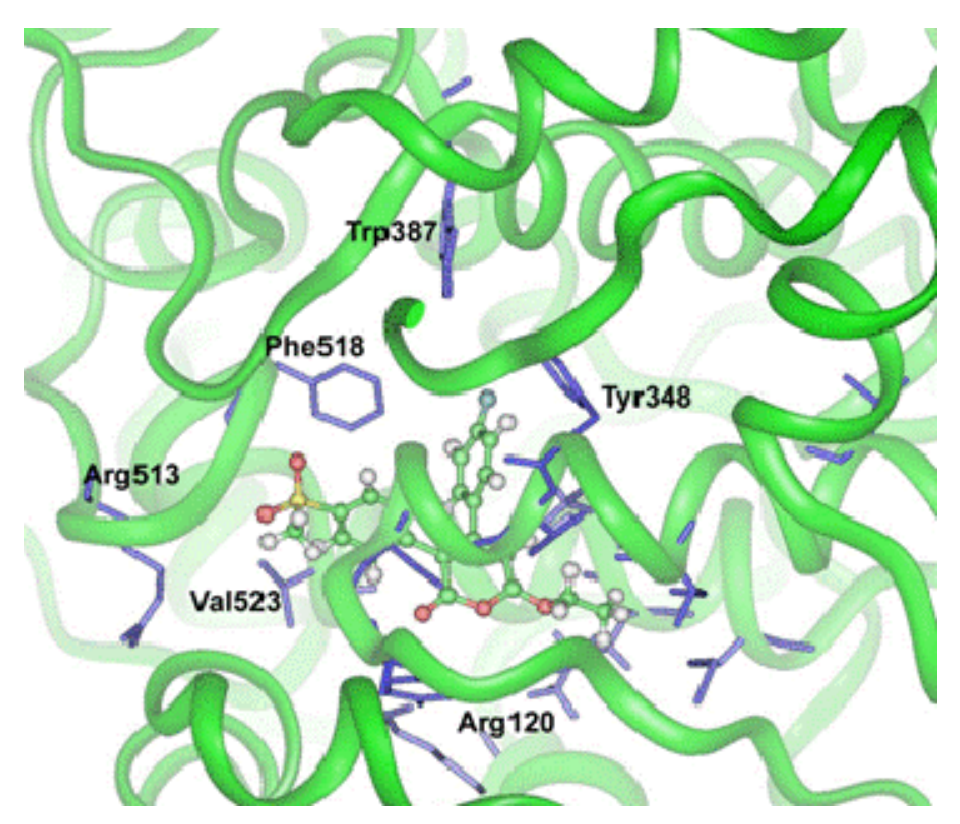

Figure 11. Docking compound 35 (ball and stick) in the binding site of murine COX-2. The figure was generated according to a previously reported method (ref 112).

The market withdrawal of some selective COX-2 inhibitors due to adverse cardiovascular events provides strong credence for the development of NO-NSAIDs as alternatives to traditional NSAIDs since NO-NSAIDs could be expected to exhibit reduced GI as well as cardiovascular side effects (116). The lipoxygenase (LOX) catalyzed biotransformation of arachidonic acid produces proinflammatory leukotrienes (LTs) via the LOX pathway (Figure 2). Accordingly, development of dual inhibitors of COX and LOX enzymes may provide superior anti-inflammatory agents with reduced GI and cardiovascular side effects (117). In addition, investigations have been undertaken to develop inhibitors of matrix metalloproteinases (MMP) and small molecule or protein based injectables that target tumor necrosis factor- $\alpha$ (TNF- $\alpha$ ) as effective anti-inflammatory agents (118, 119). While the MMP approach has given mixed indication, anti-TNF- $\alpha$ therapy has been highly successful in treating inflammatory conditions such as RA. The following sections will describe briefly some of the recent advances toward developing effective anti-inflammatory agents such as NONSAIDs, dual COX/LOX inhibitors and anti-TNF therapy.

\subsection{NO-NSAIDs}

The first reports describing NO-NSAIDs began to appear in the literature during the 1990's. NONSAIDs were investigated with the objective of abolishing the GI toxicity associated with traditional NSAID therapy since NO was known to protect the GI mucosa. These studies showed that hybrid NO-NSAIDs exhibited efficient antiinflammatory activities without causing GI side effects $(115$, 120-125). The recent adverse cardiovascular events associated with selective COX-2 inhibitor therapy has provided a strong stimulus for the development of NO-NSAIDs since NO exhibits beneficial cardiovascular effects such as vasodilation, and inhibition of platelet aggregation. The release of NO from a NO-NSAID donor prodrug that releases NO and the NSAID in vivo provides a method to counteract the adverse cardiovascular risks associated with selective COX2 inhibitors. In this regard, NitroMed Inc. developed a novel class of pyrazole analogs as selective COX-2 inhibitors containing nitrate groups as hybrid-NO donors (126). 


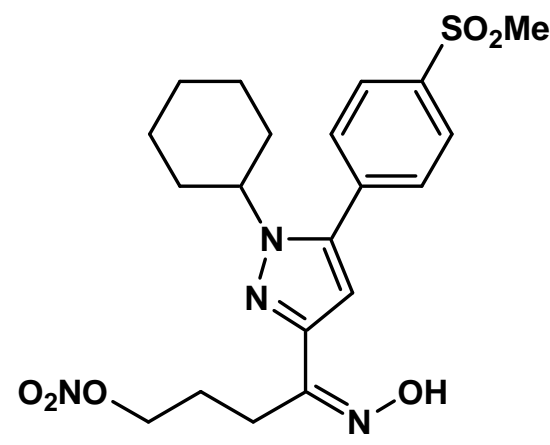

(42)<smiles>CO/[N+](=N\OCOC(=O)c1ccccc1OC(C)=O)N1CCCC1</smiles>

(44)

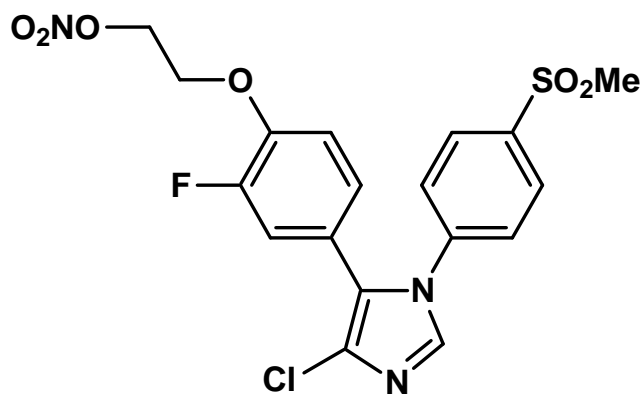

(46)

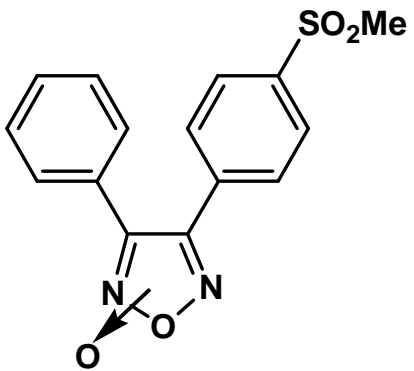

(43)<smiles>CO[N+](=NOCOC(=O)C(C)c1ccc(CC(C)C)cc1)N(C)C</smiles>

(45)

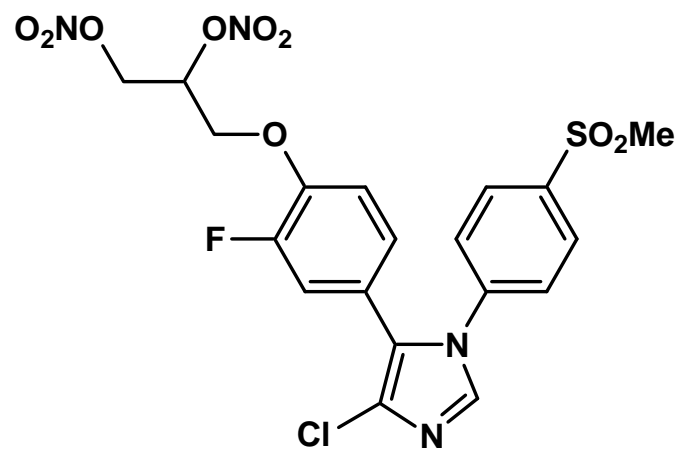

(47)

Figure 12. Examples of hybrid NO-NSAIDs.

Compound 42 (see Figure 12) exhibited potent COX-2 inhibition and selectivity (10 and 100\% inhibition of COX-1 and COX-2 isoforms respectively at a concentration of $10 \mu \mathrm{M}$ ) in conjunction with good GI tolerance (safety). Knaus and coworkers described an alternate approach approach wherein the central furanone ring system of rofecoxib was replaced by a furoxan ring. This concept was based on the observation that a furoxan ring system can act as a NO-donor (127). Therefore, 3,4-diphenylfuroxans were designed for evaluation as hybrid COX-inhibitor/NO donors. Within this class of compound, the furoxan $\mathbf{4 3}$ exhibited selective COX-2 inhibition $\left(\mathrm{COX}-2 \mathrm{IC}_{50}=11.6 \mu \mathrm{M}\right.$, COX-1 $\mathrm{IC}_{50}=0.12 \mu \mathrm{M}$; SI $\left.=97\right)$ in conjunction with NO-donor properties.

NO-NSAIDs such as aspirin, naproxen, and diclofenac have been investigated the most. In the majority of these studies, organic nitrates or nitrosothiols have been employed as the NO-donor group (115, 123-125). However, long term treatment with organic nitrates can cause "nitrate tolerance" leading to lack of GI and cardiovascular benefits (128). 


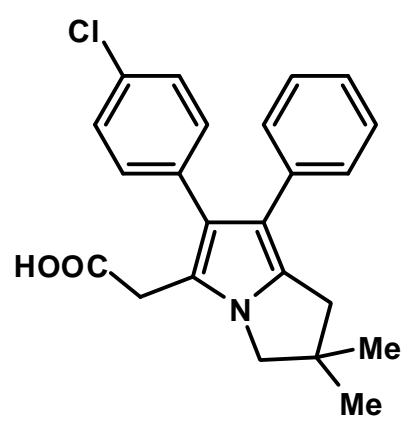

(48)

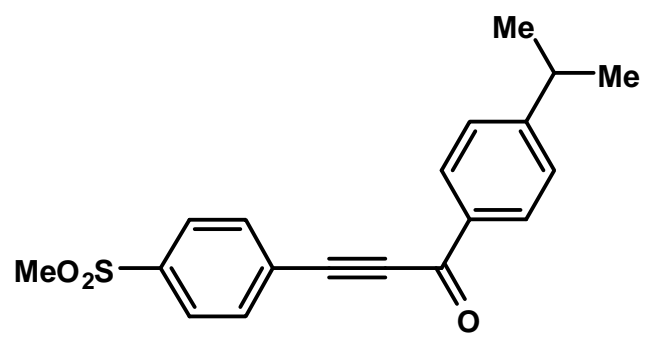

(50)

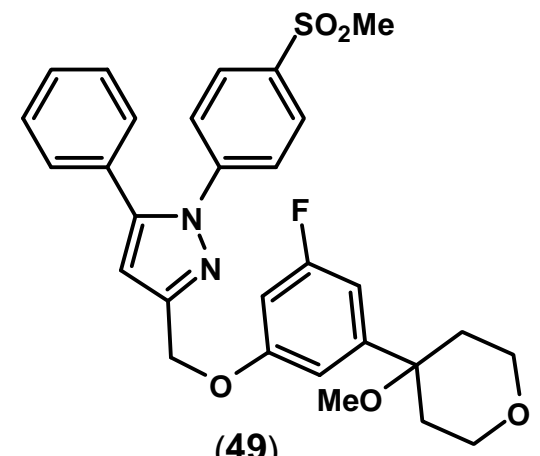

(49)

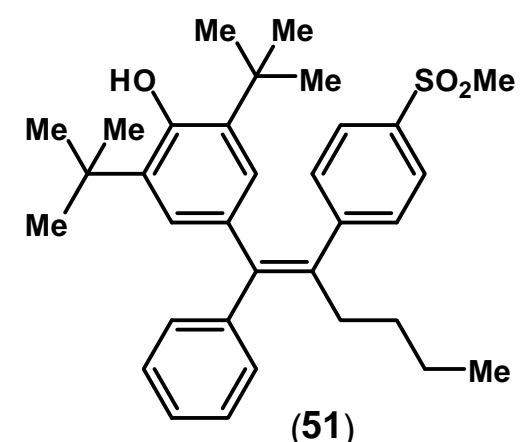

(51)

Figure 13. Examples of dual COX/LOX inhibitors.

To counter this problem Knaus and coworkers developed NO-NSAIDs containing novel diazonium-diolate groups that have the potential to theoretically release two molecules of NO with half-lives that correlate well with their pharmacological durations of action (129). The aspirin 44 and ibuprofen 45 hybrid NO-donors exhibited effective anti-inflammatory activity with reduced or no GI toxicities (Figure 12). Other aspirin analogs with NO-donor properties that exhibit platelet aggregation properties and no GI side effects have been disclosed (130).

Gasco and coworkers recently developed Cimicoxib ${ }^{\circledR}$ analogs containing organic nitrate NOdonor moieties as selective COX-2 inhibitors with vasodilator properties (Figure 12). Compounds 46 and 47 exhibited COX-2 selectivity as well as vasodilator properties (131).

\subsection{Dual COX and lipoxygenase (LOX) inhibitors}

It is well known that arachidonic acid (AA) primarily undergoes biotransformation to proinflammatory and anti-inflammatory PGs via COX mediated isoform catalysis. Lipoxygenases (LOXs), which belong to a class of non-heme ironcontaining enzymes, catalyze dioxygen incorporation into AA, to form hydroperoxide products (Figure 2). For example, AA metabolism catalyzed by 5-LOX affords proinflammatory leukotrienes (LTs) that may play a role in cardiovascular diseases since they are potent vasoconstrictors (132). In addition, other LOX mediated metabolites such as cysteinyl-LTs are known to cause GI mucosal damage (133).

ML-3000 (licofelone, 48) exhibits dual COX and 5-LOX inhibitory activities. Licofelone exhibited effective anti-inflammatory activities with reduced GI toxicities in animal models $(134,135)$. Preliminary data in humans have shown that licofelone could be an alternative to NSAIDs in treating OA $(136,137)$. In addition, hybrid NSAIDs that exhibit dual COX/5-LOX inhibition have been explored (117). In an elegant study Henichart and coworkers prepared hybrid dual COX/5-LOX inhibitors by combining COX-2 and 5-LOX pharmacophores (138). In this regard, compound 49 
possesses the pyrazole ring system present in the selective COX-2 inhibitor celecoxib in conjunction with the 5-LOX pharmacophore present in the marketed drug ZD-2138.

The dual inhibitor 49 exhibited excellent COX-2 inhibitory potency and selectivity $(\mathrm{COX}-2$ $\left.\mathrm{IC}_{50}=0.05 \mu \mathrm{M}, \mathrm{COX}-1 \quad \mathrm{IC}_{50}>10 \mu \mathrm{M} ; \mathrm{SI}>200\right)$ along with potent 5 -LOX inhibition $\left(5-\mathrm{LOX} \mathrm{IC}_{50}=\right.$ $0.03 \mu \mathrm{M})$. Other LOX isoforms such as 12-LOX and 15-LOX are known to modify low and high density lipoproteins that are implicated in atherosclerosis (139). In a recent investigation Knaus and coworkers described a novel class of diarylpropynones that exhibit dual COX and 5/15LOX inhibitory actions. Within this group of compounds, the propynone $\mathbf{5 0}$ exhibited selective COX-2 inhibition (COX-2 $\mathrm{IC}_{50}=0.32 \mu \mathrm{M}, \mathrm{COX}-1$ $\mathrm{IC}_{50}=9.2 \mu \mathrm{M}$; SI $\left.=28\right)$ and 5/15-LOX (5-LOX $\mathrm{IC}_{50}=0.32 \mu \mathrm{M}$, LOX-15 $\left.\mathrm{IC}_{50}=0.36 \mu \mathrm{M}\right)$ inhibition along with in vivo anti-inflammatory activity in animal models. In another study, the Knaus group investigated hybrid molecules where a COX-2 pharmacophore (acyclic triaryl olefin) was coupled to a redox or anti-oxidant pharmacophore (3,5-ditert-butyl-4-hydroxyphenyl, DTBHP). Compound 51 evaluated in this study exhibited dual COX/LOX inhibition $\left(\mathrm{COX}-2 \mathrm{IC}_{50}=0.36 \mu \mathrm{M}, \mathrm{COX}-1 \mathrm{IC}_{50}=\right.$ $3.0 \mu \mathrm{M}$; SI $=8.3$ and 5/15-LOX $\left(5-\operatorname{LOX} \mathrm{IC}_{50}=\right.$ $\left.0.30 \mu \mathrm{M}, \mathrm{LOX}-15 \mathrm{IC}_{50}=0.80 \mu \mathrm{M}\right)$ inhibition $(140$, 141). Related studies targeted to the design of novel COX/LOX inhibitors as effective anti-inflammatory agents with reduced side effects have been reported (142-144).

\subsection{Anti-TNF- $\alpha$ therapy}

RA is a disorder of the immune system characterized by the presence of proinflammatory cytokines in the synovium and plasma. TNF- $\alpha$ is the primary proinflammatory cytokine present in patients with RA and is known to activate other proinflammatory cytokines such as interlukin-1 (IL1) and chemokines. In the 1990's treatment of RA was revolutionized by the development of protein based therapeutics. The successful launch of protein based injectables such as etanercept (Enbrel $\left.{ }^{\circledR}\right)$, infliximab (Remicade $\left.{ }^{\circledR}\right)$ and adalimumab (Humira $\left.{ }^{\circledR}\right)$ has added an additional dimension to anti-inflammatory therapy $(119,145)$. These antiTNF monoclonal antibodies exert their beneficial effect by scavenging the proinflammatory cytokine
TNF- $\alpha$. However, recent studies have indicated that anti-TNF therapy might have adverse side effects such as latent tuberculosis, cardiovascular side effects as well as increased risk of cancer (119). This is a concern for long term therapy. Other drawbacks with anti-TNF therapy include high cost and patient compliance. Accordingly, there is interest in the design of small molecule anti-TNF agents that are orally active and may provide cost effective therapy (119).

\section{CONCLUSIONS}

NSAIDs represent an important class of compounds. The rapid discovery of selective COX-2 inhibitors can be attributed to the rational drug design approach. However, the cardiovascular side effects associated with selective COX-2 inhibitors highlights the pitfalls that may be encountered in the drug discovery paradigm. NO-NSAIDs, dual COX/LOX inhibitors and anti-TNF therapy represent novel approaches directed toward the development of effective anti-inflammatory therapy. In spite of the unprecedented advances in drug discovery, developing a safe, effective and economical therapy for treating inflammatory conditions still presents a major challenge.

\section{ACKNOWLEDGMENT}

We are grateful to the Canadian Institutes of Health Research (MOP-14712) for financial support of this research.

\section{REFERENCES}

[1]. J. R. Vane. The fight against rheumatism: from willow bark to COX-1 sparing drugs. J Physiol Pharmacol, 51:573-586, 2000 and reference cited therein.

[2]. J. R. Vane. Inhibition of prostaglandin synthesis as a mechanism of action for aspirin-like drugs. Nat New Biol, 43:232-235, 1971.

[3]. J. R. Vane. The mode of action of aspirin and similar compounds. J Allergy Clin Immunol, 58:691-712, 1976

[4]. S. Moncada, S. H. Ferreira and J. R. Vane. Prostaglandins, aspirin-like drugs and the oedema of inflammation. Nature, 246:217-219, 1973.

[5]. R. Tamblyn, L. Berkson, W. D. Dauphinee, D. Gayton, R. Grad, A. Huang, L. Isaac, P. McLeod, and L. Snell. Unnecessary prescribing 
of NSAIDs and the management of NSAIDrelated gastropathy in medical practice. Ann Intern Med, 127:429-438, (1997) and references cited therein.

[6]. J. L. Masferrer, B. S. Zweifel, K. Seibert and P. Needleman. Selective regulation of cellular cyclooxygenase by dexamethasone and endotoxin in mice. J Clin Invest, 86:1375-1379, 1990.

[7]. W. L. Xie, J. G. Chipman, D. L. Robertson, R. L. Erikson and D. L. Simmons. Expression of a mitogen-responsive gene encoding prostaglandin synthase is regulated by mRNA splicing. Proc Natl Acad Sci USA, 88:26922696, 1991.

[8]. D. A. Kujubu, and H. R. Herschman. Dexamethasone inhibits mitogen induction of the TIS10 prostaglandin synthase/cyclooxygenase gene. J Biol Chem, 267:7991-7994, 1992.

[9]. E. A. Meade, W. L. Smith and D. L. DeWitt. Differential inhibition of prostaglandin endoperoxide synthase (cyclooxygenase) isozymes by aspirin and other non-steroidal anti-inflammatory drugs. J Biol Chem, 268:6610-6614, 1993.

[10]. J. R. Vane, Y. S. Bakhle and R. M. Botting. Cyclooxygenases 1 and 2. Ann Rev Pharmacol Toxicol, 38:97-120, 1998 and references cited therein.

[11]. G. A. Fitzgerald and C. Patrono. The coxibs, selective inhibitors of cyclooxygenase-2. N Eng J Med, 345:433-442, 2001.

[12]. T. D. Penning, J. J. Talley, S. R. Bertenshaw, J. S. Carter, P. W. Collins, S. Docter, M. J. Graneto, L. F. Lee, J. W. Malecha, J. M. Miyashiro, R. S. Rogers, D. J. Rogier, S. S. Yu, G. D. Anderson, E. G. Burton, J. N. Cogburn, S. A. Gregory, C. M. Koboldt, W. E. Perkins, K. Seibert, A. W. Veenhuizen, Y. Y. Zhang and P. C. Isakson. Synthesis and biological evaluation of the 1,5-diarylpyrazole class of cyclooxygenase-2 inhibitors: identification of 4[5-(4-methylphenyl)-3-(trifluoromethyl)- $1 H$ pyrazol-1-yl]benzenesulfonamide (SC-58635, celecoxib). J Med Chem, 40:1347-1365, 1997.

[13]. P. Prasit, Z. Wang, C. Brideau, C. C. Chan, S. Charleson, W. Cromlish, D. Ethier, J. F. Evans, A. W. Ford-Hutchinson, J. Y. Gauthier, R. Gordon, J. Guay, M. Gresser, S. Kargman, B. Kennedy, Y. Leblanc, S. Leger, J. Mancini, G. P. O'Neill, M. Ouellet, M. D. Percival, H. Perrier, D. Riendeau, I. Rodger, R. Zamboni, S. Boyce, N. Rupniak, M. Forrest, D. Visco and D. Patrick. The discovery of rofecoxib, [MK 966, VIOXX, 4-(4'-methylsulfonylphenyl)-3-phenyl-2(5H)- furanone], an orally active cyclooxygenase-2 inhibitor. Bioorg Med Chem Lett, 9:1773-1778, 1999.

[14]. G. A. Fitzgerald. COX-2 and beyond: Approaches to prostaglandin inhibition in human disease. Nat Rev Drug Dis, 2:879-890, 2003.

[15]. I. Melnikova. Future of COX-2 inhibitors. Nat Rev Drug Dis, 4:453-454, 2005.

[16]. D. Mukherjee, S. E. Nissen and E. J. Topol. Risk of cardiovascular events associated with selective COX-2 inhibitors. JAMA, 286:954959, 2001 and references cited therein.

[17]. D. H. Solomon, S. Schneeweiss, R. J. Glynn, Y. Kiyota, R. Levin, H. Mogun and J. Avorn. Relationship between selective cyclooxygenase2 inhibitors and acute myocardial infarction in older adults. Circulation, 109:2068-2073, 2004.

[18]. R. S. Bresalier, R. S. Sandler, H. Quan, J. A. Bolognese, B. Oxenius, K. Horgan, C. Lines, R. Riddell, D. Morton, A. Lanas, M. A. Konstam and J. A. Baron. Cardiovascular events associated with rofecoxib in a colorectal adenoma chemoprevention trial. N Engl J Med, 352:1092-1102, 2005.

[19]. S. D. Solomon, J. J. McMurray, M. A. Pfeffer, J. Wittes, R. Fowler, P. Finn, W. F. Anderson, A. Zauber, E. Hawk and M. Bertagnolli. Cardiovascular risk associated with celecoxib in a clinical trial for colorectal adenoma prevention. N Engl J Med, 352:1071-1080, 2005.

[20]. http://www.merck.com/newsroom/vioxx/

[21]. J.-M. Dogné, C. T. Supuran and D. Pratico. Adverse cardiovascular effects of the coxibs. J Med Chem, 48:2251-2257, 2005.

[22]. $\quad$ http://www.fda.gov/cder/drug/infopage/COX2/d efault.htm

[23]. R. Watson. European medicines agency gives favorable ruling on NSAIDs. BMJ, 333:873, 2006.

[24]. C. D. Furberg. Decision by regulatory agencies: are they evidence-based?. Trials, 8:13, 2007.

[25]. E. M. Antman, J. S. Bennett, A. Daugherty, C. Furberg, H. Roberts and K. A. Taubert. Use of nonsteroidal antiinflammatory drugs: an update for clinicians: a scientific statement from the american heart association. Circulation, 115:1634-1642, 2007.

[26]. Abramovitz, M., Metters, K.M. Prostanoid receptors. Ann. Rep. Med. Chem., 33:223-231, 1998.

[27]. W. L. Smith, D. L. DeWitt and R. M. Garavito. Cyclooxygenases: structural, cellular, and molecular biology. Ann Rev Biochem, 69:145182, 2000. 
[28]. T. Miyamoto, M. Ogino, S. Yamamoto and O. Hayaishin. Purification of prostaglandin endoperoxide synthetase from bovine vesicular gland microsomes. J Biol Chem, 259:2629-2636, 1976.

[29]. D. L. DeWitt and W. L. Smith. Primary structure of prostaglandin $\mathrm{G} / \mathrm{H}$ synthase from sheep vesicular gland determined from the complementary DNA sequence. Proc Natl Acad Sci USA, 85:1412-1416, 1988.

[30]. J. P. Merlie, D. Fagan, J. Mudd and P. Needleman. Isolation and characterization of the complementary DNA for sheep seminal vesicle prostaglandin endoperoxide synthase (cyclooxygenase). J Biol Chem, 263:3550-3553, 1988.

[31]. C. Yokoyama, T. Takai and T. Tanabe. Primary structure of sheep prostaglandin endoperoxide synthase deduced from cDNA sequence. FEBS Lett, 231:347-351, 1988.

[32]. D. Picot, P. J. Loll and R. M. Garavito. The xray crystal structure of the membrane protein prostaglandin H2 synthase-1. Nature, 367:243249, 1994.

[33]. W. L. Smith and D. L. DeWitt. Prostaglandin endoperoxide $\mathrm{H}$ synthases-1 and -2 . Adv Immunol, 62:167-215, (1996).

[34]. H. Lim, B. C. Paria, S. K. Das, J. E. Dinchuk, R. Langenbach, J. M. Trzaskos and S. K. Dey. Multiple female reproductive failures in cyclooxygenase-2 deficient mice. Cell, 91:197208, 1997.

[35]. H. F. Cheng, J. L. Wang, M. Z. Zhang, Y. Miyazaki, I. Ichikawa, J. A. McKanna and R. C. Harris. Angiotensin II attenuates renal cortical cyclooxygenase-2 expression. J Clin Invest, 103:953-961, 1999.

[36]. C. D. Breder, D. L. DeWitt and R. P. Kraig. Characterization of inducible cyclooxygenase in rat brain. J Comp Neurol, 355:296-315, 1995.

[37]. C. C. Pilbeam, P. M. Fall, C. B. Alander and L. G. Raisz. Differential effects of nonsteroidal antiinflammatory drugs on constitutive and inducible prostglandin $\mathrm{G} / \mathrm{H}$ synthase in cultured bone cells. J Bone Miner Res, 12:1198-1203, 1997.

[38]. M. C. Allison, A. G. Howatson, C. J. Torrance, F. D. Lee and R. L. Russel. Gastroinestinal damage associated with the use of nonsteroidal antiiflammatory drugs. N Engl J Med, 327, 749754, 1992.

[39]. C. E. Eberhart and R. N. DuBois. Eicosanoids and gastrointestinal tract. Gastroenterology, 109:285-301, 1995.

[40]. C. J. Smith, Y. Zhang, C. M. Koboldt, J. Muhammad, B. S. Zweifel, A. Shaffer, J. J.
Talley, J. L. Masferrer, K. Seibert and P. C. Isakson. Pharmacological analysis of cyclooxygenase-1 in inflammation. Proc Natl Acad Sci USA, 95:13313-13318, 1998.

[41]. S. H. Lee, E. Soyoola, P. Chanmungam, S. Hart, W. Sun, H. Zhong, S. Liou, D. Simmons and D. Hwang. Selective expression of mitogeninducible cyclooxygenase in macrophages stimulated with lipopolysaccharide. J Biol Chem, 267:25943-25948, 1992.

[42]. K. Seibert, Y. Hang, K. Leahy, S. Hauser, J. Masferrer, W. Perkins, L. Lee and P. Isakson. Pharmacological and biochemical demonstration of the role of cyclooxygenase-2 in inflammation and pain. Proc Natl Acad Sci USA, 91:12013-12017, 1994.

[43]. P. Davies, P. J. Bailey, M. M. Goldenberg, A. W. Ford-Hutchinson. The role of arachidonic acid oxygenation products in pain and inflammation. Ann Rev Immunol, 2:335-357, 1984.

[44]. S. Karman, S. Charleson, M. Cartwright, J. Frank, D. Riendeau, J. Mancini, J. Evans and G. O'Neill. Characterization of prostaglandin $\mathrm{G} / \mathrm{H}$ synthase 1 and 2 in rat, dog, monkey and human gastrointestinal tracts. Gastroenterology, 111:445-454, 1996.

[45]. K. C. Zimmermann, M. Sarbia, K. Schor and A. A. Weber. Constitutive cyclooxygenase-2 expression in healthy human and rabbit gastric mucosa. Mol Pharmacol, 54:536-540, 1998.

[46]. H. Mizuno, C. Sakamoto, K. Matsuda, K. Wada, T. Uchida, H. Noguchi, T. Akamatsu and M. Kasuga. Induction of cyclooxygenase-2 in gastric mucosal lesions and its inhibition by specific antagonist delays healing in mice. Gastroenterology, 112:387-397, 1997.

[47]. C. Bombardier, L. Laine, A. Reicin, D. Shapiro, R. Burgos-Vargas, B. Davis, R. Day, M. B. Ferraz, C. J. Hawkey, M. C. Hochberg, T. K. Kvien and T. J. Schnitzer. VIGOR Study Group. Comparison of upper gastrointestinal toxicity of rofecoxib and naproxen in patients with rheumatoid arthritis. N Engl J Med, 343:15201528, 2000.

[48]. F. E. Silverstein, G. Faich, J. L. Goldstein, L. S. Simon, T. Pincus, A. Whelton, R/ Makuch, G. Eisen, N. M. Agrawal, W. F. Stenson, A. M. Burr, W. W. Zhao, J. D. Kent, J. B. Lefkowith, K. M. Verburg and G. S. Geis. Gastrointestinal toxicity with celecoxib vs nonsteroidal antiinflammatory drugs for osteoarthritis and rheumatoid arthritis: the CLASS study: A randomized controlled trial. JAMA, 284:1247$1255,2000$. 
[49]. T. J. Schnitzer, G. R. Burmester, E. Mysler, M. C. Hochberg, M. Doherty, E. Ehrsam, X. Gitton, G. Krammer, B. Mellein, P. Matchaba, A. Gimona, and C. J. Hawkey. TARGET Study Group. Comparison of lumiracoxib with naproxen and ibuprofen in the therapeutic arthritis research and gastrointestinal event trial (TARGET), reduction in ulcer complications: randomised controlled trial. Lancet, 364:665674, 2004.

[50]. M. Katori and M. Majima. Cyclooxygenase-2: its rich diversity roles and possible application of its selective inhibitors. Inflamm Res 49:367392, 2000.

[51]. J. E. Dinchuk, B. D. Car, R. J. Focht, J. J. Johnston, B. D. Jaffee, M. B. Covington, N. Contel, V. M. Eng, R. J. Collins, P. M. Czerniak, S. A. Gorry and J. M. Trzaskos. Renal abnormality and an altered inflammatory response in mice lacking cyclooxygenase-II. Nature, 378:406-409, 1995.

[52]. S. G. Morham, R. Lagenbach, C. D. Loftin, H. F. Tiano and N. O. Vouloumanos. Prostaglandin synthase 2 gene disruption causes severe renal pathology in mouse. Cell, 83:473-482, 1995.

[53]. W. Ye, H. Zhang, E. Hillas, D. E. Kohan, R. L. Miller, R. D. Nelson, M. Honeggar and T. Yang. Expression and function of COX isoforms in renal medulla: evidence for regulation of salt sensitivity and blood pressure. Am J Renal Physiol, 290:F542-F549, 2006.

[54]. J. Zhang, E. L. Ding and Y. Song. Adverse effects of cyclooxygenase 2 inhibitors on renal and arrhythmia events: meta-analysis of randomized trials. JAMA, 296:1619-1632, 2006.

[55]. R. C. Harris and M. D. Breyer. Update on cyclooxygenase- 2 inhibitors. Clin J Am Soc Nephrol,1:236-245, 2006.

[56]. B. F. McAdam, F. Catella-Lawson, I. A. Mardini, S. Kapoor, J. A. Lawson and G. A. FitzGerald. Systemic biosynthesis of prostacyclin by cyclooxygenase (COX)-2: the human pharmacology of a selective inhibitor of COX-2. Proc Natl Acad Sci USA, 96:272-277, 1999.

[57]. C. D. Loftin, D. B. Trivedi, H. F. Tiano, J. A. Clark, S. G. Morham, M. D. Breyer, M. Nguyen, B. M. Hawkins, J. L. Golet, O. Smithies, B. H. Koller and R. Lagenbach. Failure of ductus arteiosus closure and remodeling in neonatal mice deficient in cyclooxygenase-1 and cycloxygenase-2. Proc Natl Acad Sci USA, 98:1059-1064, 2001.

[58]. S. R. Adderley and D. J. FitzGerald. Oxidative damage of cardiomyocytes is limited by extracellular regulated kinases $1 / 2$ mediated induction of cyclooxygenanse-2. J Biol Chem, 274:5038-5046, 1999.

[59]. J. A. Mitchell and T. D. Warner. COX isoforms in the cardiovascular system: understanding the activities of nonsteroidal anti-inflammatory drugs. Nat Rev Drug Dis, 5:75-86, 2006.

[60]. Y. Cheng, M. Wang, Y. Yu, J. Lawson, C. D. Funk and G. A. Fitzgerald. Cyclooxygenases, microsomal prostaglandin E synthase-1, and cardiovascular function. J Clin Invest, 116:1391-1399, 2006.

[61]. W. R. Waddell and R. W. Loughry. Sulindac for polyposis of the colon. J Surg Oncol, 24: 83-87, 1983.

[62]. S. Kanaoka, T. Takai and K. Yoshida. Cyclooxygenase-2 and tumor biology. Adv Clin Chem, 43:59-78, 2007.

[63]. J. X. Zhu, X. Q. Song, H. P. Lin, D. C. Young, S. Q. Yan, V. E. Marquez and C. S. Chen. Using cyclooxygenase-2 inhibitors as molecular platforms to develop a new class of apoptosisinducing agents. J Natl Cancer Inst, 95:17451757, 2002.

[64]. S. Grösch, T. J. Maier, S. Schiffmann and G. Geisslinger. Cyclooxygenase-2 (COX-2)independent anticarcinogenic effects of selective COX-2 inhibitors. J Natl Cancer Inst, 98:736-747, 2006.

[65]. A. L. Hsu, T. T. Ching, D. S. Wang, X. Song, V. M. Rangnekar and C. S. Chen. The cyclooxygenase-2 inhibitor celecoxib induces apoptosis by blocking akt activation in human prostate cancer cells independently of bcl-2. J Biol Chem, 275:1397-1403, 2000.

[66]. Z. Liao, K. A. Mason and L. Milas. Cyclooxygenase- 2 and its inhibition in cancer: is there a role?. Drugs, 67:821-845, 2007.

[67]. R. S. Bresalier, R. S. Sandler, H. Quan, J. A. Bolognese, B. Oxenius, K. Horgan, C. Lines, R. Riddell, D. Morton and A. Lanas. Cardiovascular events associated with rofecoxib in a colorectal adenoma chemoprevention trial. N Engl J Med, 352:1092-1102, 2005.

[68]. J. C. Breitner, K. A. Welsh, M. J. Helms, P. C. Gaskell, B. A. Gau, A. D. Roses, M. A. PericakVance and A. M. Saunder. Delayed onset of Alzheimer's disease with nonsteroidal antiinflammatory and histamine $\mathrm{H}_{2}$ blocking drugs. Neurobiol Aging, 16:523-530, 1995.

[69]. T. A. Sandson and O. Felician. The potential application of cyclo-oxygenase type 2 inhibitors to Alzheimer's disease. Expert Opin Investig Drugs, 7:519-26, 1998.

[70]. P. S. Aisen, K. A. Schafer, M. Grundman, E. Pfeiffer, M. Sano, K. L. Davis, M. R. Farlow, S. Jin, R. G. Thomas and L. J. Thal. Effects of 
rofecoxib or naproxen vs placebo on Alzheimer's disease progression: a randomized controlled trial. JAMA, 289:2819-2826, 2003.

[71]. L. A. Kotilinek, M. A. Westerman, Q. Wang, K. Panizzon, G. P. Lim, A. Simonyi, S. Lesne, A. Falinska, L. H. Younkin, S. G. Younkin, M. Rowan, J. Cleary, R. A. Wallis, G. Y. Sun, G. Cole, S. Frautschy, R. Anwyl and K. H. Ashe. Cyclooxygenase-2 inhibition improves amyloid$\{$ beta\}-mediated suppression of memory and synaptic plasticity. Brain, 131:651-664, 2008.

[72]. L. Ho, W. Qin, B. S. Stetka and G. M. Pasinetti. Is there a future for cyclo-oxygenase inhibitors in Alzheimer's disease? CNS Drugs, 20:85-98, 2006.

[73]. Z. H. Feng, T. G. Wang, D. D. Li, P. Fung, B. C. Wilson, B. Liu, S. F. Ali, R. Lagenbach and J. S. Hong. Cyclooxygenase-2 deficient mice are resistant to 1-methyl-4-phenyl-1,2,3,6tetrahydropyridine-induced damage of dopaminergic neurons in the substantia nigra. Neurosci Lett, 329:354-358 2002.

[74]. P. Teismann, K. Tieu, D. K. Choi, D. C. Wu, A/ Naini, S. Hunot, M. Vila, V. Jackson-Lewis and S. Przedborski. Cyclooxygenase-2 is instrumental in Parkinson's disease neurodegeneration. Proc Natl Acad Sci USA, 100:5473-5478, 2003.

[75]. A. B. Reksidler, M. M. Lima, S. M. Zanata, H. B. Machado, C. da Cunha, R. Andreatini, S. Tufik and M. A. Vital. The COX-2 inhibitor parecoxib produces neuroprotective effects in MPTP-lesioned rats. Eur J Pharmacol, 560:163175, 2007.

[76]. N. V. Chandrasekharan, H. Dai, K. L. Roos, N. K. Evanson, J. Tomsik, T. S. Elton and D. L. Simmons. COX-3, a cyclooxygenase-1 variant inhibited by acetaminophen and other analgesic/antipyretic drugs: cloning, structure and expression. Proc Natl Acad Sci USA, 99:13926-13931, 2002.

[77]. R. M. Botting. Mechanism of action of acetaminophen: is there a cyclooxygenase 3? Clin Infect Dis, 31:S202-S210, 2000.

[78]. B. Kis, J. A. Snipes and D. W. Busija. Acetaminophen and the cyclooxygenase-3 puzzle: sorting out facts, fictions, and uncertainties. J Pharmacol Exp Ther, 315:1-7, 2005.

[79]. B. Hinz, O. Cheremina and K. Brune. Acetaminophen (paracetamol) is a selective cyclooxygenase-2 inhibitor in man. FASEB J, 22:383-390, 2008.

[80]. C. Luong, A. Miller, J. Barnett, J. Chow, C. Ramesha and M. F. Browner. Flexibility of the NSAID binding site in the structure of human cyclooxygenase-2. Nat Struct Biol, 3:927-933, 1996.

[81]. R. Kurumbail, A. Stevens, J. Gierse, J. McDonald, R. A. Stegeman, J. Y. Pak, D. Gildehaus, J. M. Miyashiro, T. D. Penning, K. Seibert, P. C. Isakson and W. C. Stallings. Structural basis for selective inhibition of cyclooxygenase-2 by anti-inflammatory agents. Nature, 384:644-648, 1996.

[82]. D. K. Bhattacharya, M. Lecomte, C. J. Rieke, R. M. Garavito and W. L. Smith. Involvement of arginine 120, glutamate 524 and tyrosine 355 in the binding of arachidonate and 2phenylpropionic acid inhibitors to the cyclooxygenase active site of ovine prostglandin endoperoxide $\mathrm{H}$ synthase-1. J Biol Chem, 271, 2179-2184, 1996.

[83]. J. A. Mancini, D. Riendeau, J. P. Falgueyret, P. J. Vickers and G. P. O'Neill. Arginine 120 of prostaglandin $\mathrm{G} / \mathrm{H}$ synthase-1 is required for the inhibition by nonsteroidal anti-inflammatory drugs containing a carboxylic acid moiety. J Biol Chem, 270, 29372-29377, 1995.

[84]. M. Pairet and J. van Ryn. Experimental models used to investigate the differential inhibition of cyclooxygenase- 1 and cyclooxygenase- 2 by non-steroidal-anti-inflammatory drugs. Inflamm Res, S-93-S101, 1998.

[85]. D. Riendeau, S. Charleson, W. Cromlish, J. A. Mancini, E. Wong and J. Guay. Comparison of the cyclooxygenase- 1 inhibitory properties of nonsteroidal anti-inflammatory drugs (NSAIDs) and selective COX-2 inhibitors, using sensitive microsomal and platelet assays. Can J Phys Pharmacol, 75:1088-1095, 1997.

[86]. T. D. Warner, F. Giuliano, I. Vojnovic, A. Bukasa, J. A. Mitchell and J. R. Vane. Nonsteroid drug selectivities for cyclooxygenase-1 rather than cyclo-oxygenase- 2 are associated with human gastrointestinal toxicity: a full in vitro analysis. Proc Natl Acad Sci USA, 96:7563-7568, 1999.

[87]. R. W. Friesen, C. Brideau, C. C. Chan, S. Charleson, D. Deschenes, D. Dube, D. Ethier, R. Fortin, J. Y. Gauthier, Y. Girard, R. Gordon, G. M. Greig, D. Riendeau, C. Savoie, Z. Wang, E. Wong, D. Visco, L. J. Xu and R. N. Young. 2Pyridinyl-3-(4-methylsulfonyl)phenylpyridines: selective and orally active cyclooxygenase-2 inhibitors. Bioorg Med Chem Lett, 8:2777-2782, 1998.

[88]. R. Esser, C. Berry, Z. Du, J. Dawson, A. Fox, R. A. Fujimoto, W. Haston, E. F. Kimble, J. Koehler, J. Peppard, E. Quadros, J. Quintavalla, K. Toscano, L. Urban, J. van Duzer, X. Zhang, S. Zhou and P. J. Marshall. Preclinical 
pharmacology of lumiracoxib: a novel selective inhibitor of cyclooxygenase-2. Br J Pharmacol, 44:538-550, 2005.

[89]. J. J. Talley. Selective inhibitors of cyclooxygenase-2 (COX-2). Prog Med Chem Res, 36: 201-234, 1999.

[90]. R. Huff, P. Collins, S. Kramer, K. Seibert, C. Koboldt, S. Gregory and P. A. Isakson. Structural feature of N-[2-(cyclohexyloxy)-4nitrophenyl] methanesulfonamide (NS-398) that governs its selectivity and affinity for cyclooxygenase 2 (COX-2). Inflamm Res, 44: S145-S146, 1995.

[91]. D. J. P. Pinto, R. A. Copeland, M. B. Covington, W. J. Pitts, D. G. Batt, M. J. Orwat, G. Lam, A. Joshi, Y. C. Chan, S. Wang, J. M. Trzaskos, R. L. Magolda and D. M. Kornhauser. Chemistry and pharmacokinetics of diarylthiophenes and terphenyls as selective COX-2 inhibitors. Bioorg Med Chem Lett, 6:2907-2912, 1996.

[92]. Y. Leblanc, J. Y. Gauthier, D. Ethier, J. Guay, J. Mancini, D. Riendeau, P. Tagari, P. Vickers, E. Wong and P. Prasit. Synthesis and biological evaluation of 2,3-diarylthiophenes as selective COX-2 and COX-1 inhibitors. Bioorg Med Chem Lett, 5:2123-2128, 1995.

[93]. S. R. Bertenshaw, J. J. Talley, D. J. Rogier, M. J. Graneto, R. S. Rogers, S. W. Kramer, T. D. Penning, C. M. Koboldt, A. W. Veenhuizen, Y. Zhang and W. E. Perkins. 3,4-Diarylthiophenes are selective COX-2 inhibitors. Bioorg Med Chem Lett, 5:2919-2122, 1995.

[94]. Li, J. J.; Anderson, G. D.; Gregory, S. A.; Huang, H. C.; Isakson, P. C.; Koboldt, C. M.; Logusch, E. W.; Norton, M. B.; Perkins, W. E.; Reinhard, E. J.; Seibert, K.; Veenhuizen, A. W. 1,2-Diarylcyclopentenes as selective cyclooxygenase- 2 inhibitors and orally active antiinflammatory agents. J Med Chem, 38:4570-4578, (1998).

[95]. A. G. Habeeb, P. N. P. Rao and E. E. Knaus. Design and synthesis of celecoxib and rofecoxib analogues as selective cyclooxygenase-2 (COX2) inhibitors: replacement of sulfonamide and methylsulfonyl pharmacophores by an azido bioisostere. J Med Chem, 44:3039-3042, 2001.

[96]. J. M. Uddin, P. N. P. Rao and E. E. Knaus. Design and synthesis of novel celecoxib analogs as selective cyclooxygenase-2 (COX-2) inhibitors: replacement of the sulfonamide pharmacophore by a sulfonylazide bioisostere. Bioorg Med Chem, 11:5273-5280, 2003.

[97]. O. Llorens, J. L. Perez, A. Palomer and D. Mauleon. Structural basis for dynamic mechanism of ligand binding to COX. Bioorg Med Chem Lett, 9:2779-2784, 1999.
[98]. M. Pal, M. Madan, S. Padakanti, V. R. Pattabiraman, S. Kalleda, A. Vanguri, R. Mullangi, N. V. Mamidi, S. R. Casturi, A. Malde, B. Gopalakrishnan and K. R. Yeleswarapu. Synthesis and cyclooxygenase-2 inhibiting property of 1,5-diarylpyrazoles with substituted benzenesulfonamide moiety as pharmacophore: preparation of sodium salt for injectable formulation. J Med Chem, 46:39753984, 2003.

[99]. S. K. Singh, S. Vobbalareddy, S. R. Kalleda, S. R. Casturi, S. R. Datla, R. N. Mamidi, R. Mullangi, R. Ramanujam, K. R. Yeleswarapu and J. Iqbal. Identification of 2-hydroxymethyl4-[5-(4-methoxyphenyl)-3-trifluoromethylpyrazol-1-yl]-N-propionylbenzenesulfonamide sodium as a potential COX-2 inhibitor for oral and parenteral administration. Bioorg Med Chem, 14:8626-8634, 2006.

[100]. J. J. Talley, D. L. Brown, J. S. Carter, M. J. Graneto, C. M. Koboldt, J. L. Masferrer, W. E. Perkins, R. S. Rogers, A. F. Shaffer, Y. Y. Zhang, B. S. Zweifel and K. Seibert. 4-[5Methyl-3-phenylisoxazol-4-yl]-

benzenesulfonamide, valdecoxib: a potent and selective inhibitor of COX-2. J Med Chem, 43:775-777, 2000.

[101]. M. L. Chavez and C. J. DeKorte. Valdecoxib: a review. Clin Ther, 25:817-851, 2003.

[102]. C. B. Joubert, E. Lorthiois and F. Moreau. To market, to market. Ann Rep Med Chem, 38:347-374, 2003.

[103]. A. G . Habeeb, P. N. P. Rao and E. E. Knaus. Design and syntheses of diarylisoxazoles: novel inhibitors of cyclooxygenase-2 (COX-2) with analgesic-antiinflammatory activities. Drug Dev Res, 51:273-286, 2001.

[104]. C. C. Chan, S. Boyce, C. Brideau, S. Charleson, W. Cromlish, D. Ethier, J. Evans, A. W. FordHutchinson, M. J. Forrest, J. Y. Gauthier, R. Gordon, M. Gresser, J. Guay, S. Kargman, B. Kennedy, Y. Leblanc, S. Leger, J. Mancini, G. P. O'Neill, M. Ouellet, D. Patrick, M. D. Percival, H. Perrier, P. Prasit, I. Rodger, P. Tagari, M. Therien, P. Vickers, D. Visco, Z. Wang, J. Webb, E. Wong, L. J. Xu, R. N. Young, R. Zamboni and D. Riendeau. Rofecoxib [Vioxx, MK-0966; 4-(4'-methylsulfonylphenyl)-3phenyl-2-(5H)-furanone]: a potent and orally active cyclooxygenase-2 inhibitor. Pharmacological and biochemical profiles. J Pharmacol Exp Ther, 290:551-560, 1999.

[105]. Y. Leblanc, P. Roy, Z. Wang, C. S. Li, N. Chauret, D. A. Nicoll-Griffith, J. M. Silva, Y. Aubin, J. A. Yergey, C. C. Chan, D. Riendeau, C. Brideau, R. Gordon, L. Xu, J. Webb, D. M. 
Visco and P. Prasit. Discovery of a potent and selective COX-2 inhibitor in the alkoxy lactone series with optimized metabolic profile. Bioorg Med Chem Lett, 12:3317-3320, 2002.

[106]. W. C. Black, C. Brideau, C. C. Chan, S. Charleson, W. Cromlish, R. Gordon, E. L. Grimm, G. Hughes, S. Leger, C. S. Li, D. Riendeau, M. Therien, Z. Wang, L. J. Xu and P. Prasit. 3,4-Diaryl-5-hydroxyfuranones: highly selective inhibitors of cyclooxygenase-2 with aqueous solubility. Bioorg Med Chem Lett, 13:1195-1198, 2003.

[107]. M. A. Rahim, P. N. P. Rao and E. E. Knaus. Isomeric acetoxy analogues of rofecoxib: a novel class of highly potent and selective cyclooxygenase-2 inhibitors. Bioorg Med Chem Lett, 12:2753-2756, 2002.

[108]. N. Chauret, J. A. Yergey, C. Brideau, R. W. Friesen, J. Mancini, D. Riendeau, J. Silva, A. Styhler, L. A. Trimble and D. A. Nicoll-Griffith. In vitro metabolism considerations, including activity testing of metabolites, in the discovery and selection of the COX-2 inhibitor etoricoxib (MK-0663). Bioorg Med Chem Lett, 11:10591062, 2001.

[109]. C. P. Cannon, S. P. Curtis, G. A. FitzGerald, H. Krum, A. Kaur, J. A. Bolognese, A. S. Reicin, C. Bombardier, M. E. Weinblatt, D. van der Heijde, E. Erdmann and L. Laine. Cardiovascular outcomes with etoricoxib and diclofenac in patients with osteoarthritis and rheumatoid arthritis in the multinational etoricoxib and diclofenac arthritis long-term (MEDAL) programme: a randomised comparison. Lancet, 368:1771-81, 2006.

[110]. C. S. Li, C. Brideau, C. C. Chan, C. Savoie, D. Claveau, S. Charleson, R. Gordon, G. Greig, J. Y. Gauthier, C. K. Lau, D. Riendeau, M. Therien, E. Wong and P. Prasit. Pyridazinones as selective cyclooxygenase-2 inhibitors. Bioorg Med Chem Lett, 13:597-600, 2003.

[111]. P. N. P. Rao, A. Amini, H. Li, A. G. Habeeb and E. E. Knaus. Design, synthesis and biological evaluation of 6-substituted-3-(4methanesulfonylphenyl)-4-phenylpyran-2-ones: a novel class of diarylheterocyclic selective cyclooxygenase-2 inhibitors J Med Chem, 46:4872-4882, 2003.

[112]. P. N. P. Rao, M. J. Uddin and E. E. Knaus. Design, synthesis, and structure-activity relationship studies of 3,4,6-triphenylpyran-2ones as selective cyclooxygenase-2 inhibitors. J Med Chem, 47:3972-3990, 2004.

[113]. Y. H. Joo, J. K. Kwan, S. H. Kang, M. S. Noh, J. Y. Ha, J. K. Kyu, K. M. Min, C. H. Hoon and S. Chung. 2,3-Diarylbenzopyran derivatives as a novel class of selective cyclooxygenase-2 inhibitors. Bioorg Med Chem Lett, 13:413-417, 2003.

[114]. S. Moncada. Nitric oxide in the vasculature: physiology and pathophysiology. Ann N Y Acad Sci, 811:60-67, 1997.

[115]. J. L. Wallace, L. J. Ignarro and S. Fiorucci. Potential cardioprotective actions of NOreleasing aspirin. Nat. Rev. Drug Disc, 1: 375382, 2002.

[116]. A. G. Herman and S. Moncada. Therapeutic potential of nitric oxide donors in the prevention and treatment of atherosclerosis. Eur Heart J, 26:1945-1955, 2005.

[117]. C. Charlier and C. Michaux. Dual inhibition of cyclooxygenase-2 (COX-2) and 5-lipoxygenase $(5-\mathrm{LOX})$ as a new strategy to provide safer nonsteroidal anti-inflammatory drugs. Eur J Med Chem, 38: 645-659, 2003 and references sited therein.

[118]. J. Hu, P. E. Van den Steen, Q. X. Sang and G. Opdenakker. Matrix metalloproteinase inhibitors as therapy for inflammatory and vascular diseases. Nat Rev Drug Disc, 6:480497, 2007.

[119]. M. A. Palladino, F. R. Bahjat, E. A. Theodorakis and L. L. Moldaver. Anti-TNF- $\alpha$ therapies: the next generation. Nat Rev Drug Disc, 2:736-746, 2003.

[120]. J. L. Wallace, B. Reuter, C. Cicala, W. McKnight, G. Cirino and M. B. Gisham. Novel nonsteroidal antiinflammatory drug derivatives with markedly reduced ulcerogenic properties in rats. Gastroenterology, 107:173-179, 1994.

[121]. J. L. Wallace, B. Reuter, C. Cicala, W. McKnight, M. B. Grisham and G. A. Cirino. Diclofenac derivative without ulcerogenic properties. J Pharmacol, 257: 249-255, 1994.

[122]. S. N. Elliott, W. McKnight, G. Cirino and J. L. Wallace. A nitric oxide-releasing nonsteroidal antiinflammatory drug accelerates gastric ulcer healing in rats. Gastroenterology, 109:524-530, 1995.

[123]. M. N. Muscara, W. McNight, P. Del Soldato and J. L. Wallace. Effects of a nitric oxidereleasing naproxen derivative on hypertension and gastric damage induced by chronic nitric oxide inhibition in the rat. Pharmacol Lett, 62:235-240, 1998.

[124]. R. E. Kartasasmita, S. Laufer and J. Lehmann. NO-donors (VII [I]): synthesis and cyclooxygenase inhibitory properties of $\mathrm{N}$ - and S-nitrooxypivaloyl-cysteine derivatives of naproxen - a novel type of No-NSAID. Arch Pharm, 335:363-366, 2002. 
[125]. U. K. Bandarage, L. Chen, X. Fang, D. S. Garvey, A. Glavin, D. R. Janero, L. G. Letts, G. J. Mercer, J. K. Saha, J. D. Schroeder, M. J. Shumway and S. W. Tam. Nitrosothiol esters of diclofenac: synthesis and pharmacological chracterization as gastrointestinal-sparing prodrugs. J Med Chem, 43: 4005-4016, 2000.

[126]. R. R. Ranatunge, M. Augustyniak, U. K. Bandarage, R. A. Earl, J. L. Ellis, D. S. Garvey, D. R. Janero, L. G. Letts, A. M. Martino, D. R. Murty, M. G. Murty, S. K. Richardson, J. Schroeder, M. J. Shumway, S. W. Tam, A. M. Trocha and D. V. Young. Synthesis and selective cyclooxygenase-2 inhibitory activity of a series of novel, nitric oxide donorcontaining pyrazoles. J Med Chem, 47:21802193, 2004.

[127]. C. Velázquez, P. N. P. Rao, R. McDonald and E. E. Knaus. Synthesis and biological evaluation of 3,4-diphenyl-1,2,5-oxadiazole-2-oxides and 3,4-diphenyl-1,2,5-oxadiazoles as potential hybrid COX-2 inhibitor/nitric oxide donor agents. Bioorg Med Chem, 13:2749-2757, 2005.

[128]. T. Csont and P. Ferdinandy. Cardioprotective effects of glyceryl trinitrate: beyond vascular nitrate tolerance. Pharmacol Ther, 105:57-68, 2005.

[129]. C. Velázquez, P. N. P. Rao, R. McDonald and E. E. Knaus. Novel nonsteroidal antiinflammatory drugs possessing a nitric oxide donor diazen-1ium-1,2-diolate moiety: design, synthesis, biological evaluation, and nitric oxide release studies. J Med Chem, 48:4061-4067, 2005.

[130]. L. Lazzarato, M. Donnola, B. Rolando, E. Marini, C. Cena, G. Coruzzi, E. Guaita, G. Morini, R. Fruttero, A. Gasco and S. Biondi. Searching for new NO-donor aspirin-like molecules: a new class of nitrooxy-acyl derivatives of salicylic acid. J Med Chem, 51:1894-1903, 2008.

[131]. K. Chegaev, L. Lazzarato, P. Tosco, C. Cena, E. Marini, B. Rolando, P. A. Carrupt, R. Fruttero and A. Gasco. NO-donor COX-2 inhibitors. new nitrooxy-substituted 1,5-diarylimidazoles endowed with COX-2 inhibitory and vasodilator properties. J Med Chem, 50:1449-1457, 2007.

[132]. G. de Gaetano, M. B. Donati and C. Cerletti. Prevention of thrombosis and vascular inflammation: benefits and limitations of selective or combined COX-1, COX-2 and 5LOX inhibitors. Trends Pharmacol Sci, 24:245252, 2003.

[133]. J. L. Wallace, C. M. Keenan and D. N. Granger. Gastric ulceration induced by nonsteroidal antiinflammatory drugs is a neutrophil-dependent process. Am J Physiol, 259:G462-G467, 1990.
[134]. S. A. Laufer, J. Augustin, G. Dannhardt and W. Kiefer. (6,7-Diaryldihydropyrrolizin-5-yl)acetic acids, a novel class of potent dual inhibitors of both cyclooxygenase and 5-lipoxygenase. J Med Chem, 37:1894-1897, 1994.

[135]. S. Fiorucci, R. Meli, M. Bucci and G. Cirino. Dual inhibitors of cyclooxygenase and 5lipoxygenase. A new avenue in antiinflammatory therapy?. Biochem Pharmacol, 62:1433-1438, 2001.

[136]. A. F. Cicero and L. Laghi. Activity and potential role of licofelone in the management of osteoarthritis. Clin Interv Aging, 2:73-79, 2007.

[137]. J. M. Alvero-Gracia. Licofelone-clinical update on a novel LOX/COX inhibitor for the treatment osteoarthritis. Rheumatology, 43:i21i25, 2004.

[138]. S. Barbey, L. Goossens, T. Taverne, J. Cornet, V. Choesmel, C. Rouaud, G. Gimeno, S. Yannic-Arnoult, C. Michaux, C. Charlier, R. Houssin and J. P. Henichart. Synthesis and activity of a new methoxytetrahydropyran derivative as dual cyclooxygenase-2/5lipoxygenase inhibitor. Bioorg Med Chem Lett, 12: 779-782, 2002.

[139]. H. Kuhn and V. B. O’Donnell. Inflammation and immune regulation by $12 / 15$-lipoxygenases. Prog Lipid Res, 45:334-356, 2006.

[140]. P. N. P. Rao, Q. H. Chen and E. E. Knaus. Synthesis and structure-activity relationship studies of 1,3-diarylprop-2-yn-1-ones: dual inhibitors of cyclooxygenases and lipoxygenases. J Med Chem, 49: 1668-1683, 2006.

[141]. A. Moreau, P. N. P. Rao and E. E. Knaus. Synthesis and biological evaluation of acyclic triaryl (Z)-olefins possessing a 3,5-di-tert-butyl4-hydroxyphenyl pharmacophore: dual inhibitors of cyclooxygenases and lipoxygenases. Bioorg Med Chem Lett, 14:5340-5350, 2006.

[142]. A. A. Geronikaki, A. A. Lagunin, D. I. Hadjipavlou-Litina, P. T. Eleftheriou, D. A. Filimonov, V. V. Poroikov, I. Alam and A. K. Saxena. Computer-aided discovery of antiinflammatory thiazolidinones with dual cyclooxygenase/lipoxygenase inhibition. J Med Chem, 51:1601-1609, 2008.

[143]. M. V. Reddy, V. K. Billa, V. R. Pallela, M. R. Mallireddigari, R. Boominathan, J. L. Gabriel and E. P. Reddy. Design, synthesis, and biological evaluation of 1-(4-sulfamylphenyl)3-trifluoromethyl-5-indolyl pyrazolines as cyclooxygenase-2 (COX-2) and lipoxygenase 
(LOX) inhibitors. Bioorg Med Chem, 16:39073916, 2008.

[144]. Q. H. Chen, P. N. P. Rao and E. E. Knaus. Synthesis and biological evaluation of a novel class of rofecoxib analogues as dual inhibitors of cyclooxygenases (COXs) and lipoxygenases (LOXs). Bioorg Med Chem Lett, 14:7898-7909, 2006.

[145]. M. Wong, D. Ziring, Y. Korin, S. Desai, S. Kim, J. Lin, D. Gjertson, J. Braun, E. Reed and R. R. Singh. TNF- $\alpha$ blockade in human diseases: mechanisms and future directions. Clin Immunol, 126:121-136, 2008. 